\title{
Inhibition of Allogeneic and Autologous T Cell Proliferation by Adipose-Derived Mesenchymal Stem Cells of Ankylosing Spondylitis Patients
}

\author{
Ewa Kuca-Warnawin $\mathbb{D}^{1},{ }^{1}$ Magdalena Plebańczyk $\mathbb{D}^{1},{ }^{1}$ Krzysztof Bonek, $^{2}$ and Ewa Kontny $\mathbb{D}^{1}$ \\ ${ }^{1}$ Department of Pathophysiology and Immunology, National Institute of Geriatrics, Rheumatology and Rehabilitation, \\ Warsaw 02-637, Poland \\ ${ }^{2}$ Department of Rheumatology, National Institute of Geriatrics, Rheumatology and Rehabilitation, Warsaw 02-637, Poland \\ Correspondence should be addressed to Ewa Kuca-Warnawin; ewa.kuca-warnawin@spartanska.pl
}

Received 26 October 2020; Revised 17 January 2021; Accepted 15 February 2021; Published 12 March 2021

Academic Editor: Jess Frith

Copyright (c) 2021 Ewa Kuca-Warnawin et al. This is an open access article distributed under the Creative Commons Attribution License, which permits unrestricted use, distribution, and reproduction in any medium, provided the original work is properly cited.

Background. In ankylosing spondylitis (AS), accompanied by chronic inflammation, T cell expansion plays a pathogenic role; the immunoregulatory properties of bone marrow-derived mesenchymal stem cells (BM-MSCs) are impaired, while functional characteristics of their adipose tissue-derived counterparts are (ASCs) unknown. Methods. We evaluated the antiproliferative activity of AS/ASCs, obtained from 20 patients, towards allogeneic and autologous T lymphocytes, using ASCs from healthy donors (HD/ASCs) as the reference cell lines. The PHA-activated peripheral blood mononuclear cells (PBMCs) were cocultured in cell-cell contact and transwell conditions with untreated or TNF+IFN $\gamma$ - (TI-) licensed ASCs, then analyzed by flow cytometry to identify proliferating and nonproliferating $\mathrm{CD}^{+}$and $\mathrm{CD}^{+} \mathrm{T}$ cells. The concentrations of kynurenines, prostaglandin $\mathrm{E}_{2}\left(\mathrm{PGE}_{2}\right)$, and IL-10 were measured in culture supernatants. Results. In an allogeneic system, HD/ASCs and AS/ASCs similarly decreased the proliferation of $\mathrm{CD}^{+}$and $\mathrm{CD}^{+} \mathrm{T}$ cells and acted mainly via soluble factors. The concentrations of kynurenines and $\mathrm{PGE}_{2}$ inversely correlated with $\mathrm{T}$ cell proliferation, and selective inhibitors of these factors synthesis significantly restored T cell response. AS/ASCs exerted a similar antiproliferative impact also on autologous T cells. Conclusion. We report for the first time that despite chronic in vivo exposure to inflammatory conditions, AS/ASCs retain the normal capability to restrain expansion of allogeneic and autologous $\mathrm{CD} 4^{+}$and $\mathrm{CD} 8^{+} \mathrm{T}$ cells, act primarily via kynurenines and $\mathrm{PGE}_{2}$, and thus may have potential therapeutic value. Some distinctions between the antiproliferative effects of AS/ASCs and $\mathrm{HD} / \mathrm{ASC}$ suggest in vivo licensing of AS/ASCs.

\section{Introduction}

Ankylosing spondylitis (AS) is a rheumatic disease characterized by chronic inflammation and pathological new bone formation at axial joints with resulting spinal segment fusion. Peripheral arthritis, enthesitis, osteoporosis, and extraskeletal symptoms, such as involvement of the eye, skin, or gut, are also common [1]. It is proposed that immune barrier dysfunction (gut, skin) and/or aberrant immune reactions at sites of mechanical stress (entheses, vessel walls), together with mutual interactions between innate and adaptive immune mechanisms, are critical for triggering, development, and regulation of AS [2]. The striking association of
AS with HLA-B $* 27$ alleles and epistatic interactions with alleles encoding endoplasmic reticulum aminopeptidases (ERAP) indicate a key pathogenic role of antigen presentation to $\mathrm{T}$ cells, followed by development and persistence of adaptive immune response, which involves primarily $\mathrm{T}$ cell subsets [3]. In AS patients, T cells predominate in early and active sacroiliitis and represent about $50 \%$ of cells infiltrating affected joints $[4,5]$. Increased number and greater proliferation of $\mathrm{CD}^{+}$and $\mathrm{CD} 8^{+} \mathrm{T}$ cells were found in both the synovial fluid and peripheral blood of these patients [6-9]. Mesenchymal stromal/stem cells (MSCs), present in various tissues, are endowed with immunomodulatory potency. These cells are known to exert immunosuppressive effects 
on different immune cells, including T lymphocytes [10]. Acting via soluble mediators and cell contact-dependent pathways, MSCs inhibit activation, and proliferation of $\mathrm{T}$ cells suppress effector but protect or induce regulatory $\mathrm{T}$ cells (Treg) [11]. Among numerous soluble factors, prostaglandin $\mathrm{E}_{2}\left(\mathrm{PGE}_{2}\right)$ and indoleamine-2,3-dioxygenase (IDO)/kynurenine pathway are regarded as the main mediators of immunosuppressive activity of human MSCs, including inhibition of T cell proliferation [12-14]. To improve the therapeutic features of MSCs for successful clinical application, several strategies were developed, and preconditioning with proinflammatory cytokines, e.g., tumor necrosis factor (TNF) and interferon $\gamma$ (IFN $\gamma$ ), is commonly used [15]. Importantly, bone marrowderived MSCs (BM-MSCs) from AS patients show abnormalities in gene expression, secretory potential, and reduced immunomodulatory activity [16-18]. Moreover, BM-MSCs are suggested to contribute to abnormal bone homeostasis, characteristic of AS, because of their strong capacity to inhibit osteoclastogenesis as well as enhanced osteoblastogenic and adipogenic differentiation [19-21]. Therefore, in currently ongoing clinical trials allogeneic, but not autologous, MSCs of various tissue origin are used for AS patients' treatment. However, adipose-derived mesenchymal stem cells (ASCs), known to possess stronger immunosuppressive properties than BM-MSC [14], have not been tested yet [22]. Moreover, in rheumatic diseases, bone marrow is the site where inflammation takes place, which is in contrast to not affected peripheral adipose tissue [23]. Interestingly, promising results of the application of autologous stromal vascular fraction (SVF), containing adipose-derived mesenchymal stem cells (ASCs), suggest the therapeutic use of those cells in AS [24]. Unfortunately, the biology of ASCs of AS patients (AS/ASCs) is poorly understood, and data about immunomodulatory properties of AS/ASCs are missing. We have previously found that ASCs of AS patients (AS/ASCs) show certain abnormalities in the expression of surface markers and secretion of soluble factors but retain the capability to regulate the expression of $\mathrm{T}$ cell activation markers $[25,26]$. Considering an important role of $\mathrm{T}$ cells in AS pathogenesis and the potential therapeutic application of autologous ASCs, in the present study, we have focused on further evaluation of the immunoregulatory potential of AS/ASCs, by assessing antiproliferative activity and mechanism (s) of action of these cells on allogeneic and autologous $\mathrm{CD}^{+}$and $\mathrm{CD}^{+} \mathrm{T}$ lymphocytes. To this aim, mitogenstimulated peripheral blood mononuclear cells (PBMCs) were cocultured with untreated or TNF + IFN $\gamma$ (TI) preconditioned ASCs, obtained from AS patients and healthy donors (HD); then, the proliferation of $\mathrm{CD} 4^{+}$and $\mathrm{CD}^{+} \mathrm{T}$ lymphocytes as well as the release of PGE2, kynurenines, and interleukin(IL-) 10 was analyzed. The contribution of soluble mediators to immunomodulatory ASCs action was verified by preventing cell-cell contact, using the transwell system, and application of specific inhibitors of $\mathrm{PGE}_{2}$ and kynurenine synthesis.

\section{Materials and Methods}

2.1. Patients and Sample Collection. A group of 20 patients (8 females, 12 males) who fulfilled the ASAS (Assessment of SpondyloArthritis International Society) criteria for AS [27] were included in the study. Patients' characteristics are given in Table 1. This study meets all criteria contained in the Declaration of Helsinki and was approved by the Ethics Committee of the National Institute of Geriatrics, Rheumatology, and Rehabilitation, Warsaw, Poland (the approval protocol no: KBT-8/4/20016). All patients gave their written informed consent before enrolment.

2.2. ASC Isolation and Culture. Specimens of subcutaneous abdominal fat were taken from the patients by an $18 \mathrm{G}$ needle biopsy. Tissue processing, ASC isolation, and culture were performed as described previously [28]. Five human adipose-derived mesenchymal cell lines (Lonza Group, Lonza Walkershille Inc., MD, USA; donor numbers: 0000440549, 0000410252, 0000535975, 0000605220, 0000550179) were used as a control. All experiments were performed using ASCs at 3-5 passages. ASCs were cultured in a complete culture medium composed of DMEM/F12 (PAN Biotech UK Ltd., Wimborn, UK), 10\% fetal calf serum (FCS) (Biochrom, Berlin, Germany), $200 \mathrm{U} / \mathrm{ml}$ penicillin, $200 \mu \mathrm{g} / \mathrm{ml}$ streptomycin (Polfa Tarchomin S.A., Warsaw, Poland), and $5 \mu \mathrm{g} / \mathrm{ml}$ plasmocin (InvivoGen, San Diego, CA, USA). Preconditioning ("priming" or "licensing") of ASCs with proinflammatory cytokines was performed by stimulation of the cells for $24 \mathrm{~h}$ with human recombinant tumor necrosis factor (TNF) and interferon $\gamma($ IFN $\gamma)$ (both from R\&D Systems, Minneapolis, MN, USA; each applied at $10 \mathrm{ng} / \mathrm{ml}$ ). The concentration of TNF and IFN $\gamma$ was determined based on previous publications [29-31].

2.3. Contacting and Noncontacting Cocultures of ASCs with Peripheral Blood Mononuclear Cells (PBMCs). All cocultures were performed in the complete DMEM/F12 medium. ASCs $\left(6 \times 10^{4} /\right.$ well $/ 2 \mathrm{ml}$ of medium $)$ were seeded into 24 -well plates and stimulated with IFN $\gamma$ and TNF (see above). PBMCs were isolated from buffy coats obtained from healthy male honorary blood donors ( $<60$ years old) and AS patients, according to routinely applied procedure with the use of Ficoll-Paque (GE Healthcare, Uppsala, Sweden). After isolation, PBMCs $\left(1.2 \times 10^{6} /\right.$ well $/ 2 \mathrm{ml}$ of medium $)$ were seeded either directly (contacting coculture) or on a $0.4 \mu \mathrm{m}$ pore size Transwell filters (MD24 with a carrier for inserts $0.4 \mathrm{MY}$, Thermo Fisher Scientific, Massachusetts, MA, USA) (noncontacting coculture) into 24-well plates with adherent ASCs $\left(6 \times 10^{4} /\right.$ well $)$ and treated with $2.5 \mu \mathrm{g} / \mathrm{ml}$ of phytohaemagglutinin (PHA, Sigma-Aldrich, St. Louis, MO, USA). After 5 days of coculture, culture supernatants (SNs) and PBMCs were harvested for further analysis, i.e., the measurement of the concentrations of soluble factors-kynurenines, $\mathrm{PGE}_{2}$, and IL-10 or flow cytometry, respectively. PBMCs cultured separately were used as control.

2.4. The Measurement of Soluble Factors in Culture Supernatants. Kynurenine concentration was measured spectrophotometrically as described elsewhere [32]. To this aim, SNs were mixed with $30 \%$ trichloroacetic acid at a $2: 1$ ratio and incubated for $30 \mathrm{~min}$ at $5^{\circ} \mathrm{C}$, then centrifuged at $10000 \times \mathrm{g}$ for $5 \mathrm{~min}$ and finally diluted at a $1: 1$ ratio in Ehrlich's reagent ( $100 \mathrm{mg}$ p-dimethyl benzaldehyde and 
TABLE 1: Demographic and clinical characteristics of the patients.

\begin{tabular}{lc}
\hline Parameters & $\begin{array}{c}\text { Ankylosing spondylitis (AS) } \\
(n=20)\end{array}$ \\
\hline Demographics & $42.0(25-70)$ \\
Age, years & $8 \mathrm{~F} / 12 \mathrm{M}$ \\
Sex, female (F)/male (M), $n$ & $6(1.5-18)$ \\
Disease duration, years & \\
Clinical data & $6.1(1.0-8.2)$ \\
BASDAI, score & $3.8(1-4.7)$ \\
ASDAS CRP, score & $5.0(0-9.6)$ \\
BASFI, score & $4.2(0.25-7.2)$ \\
BASMI, score & $1.125(0-2.75)$ \\
HAQ, score & \\
Laboratory values & $7(5-59)$ \\
CRP, mg/l & $15(1-59)$ \\
ESR, mm/h & \\
Medications, \% & 80.0 \\
NSAIDs & 30.0 \\
Nonbiologic DMARDs & 10.0 \\
Glucocorticosteroids &
\end{tabular}

$5 \mathrm{ml}$ glacial acetic acid; Sigma-Aldrich, St. Louis, MO, USA). The optical density of the samples was measured at a wavelength of $490 \mathrm{~nm}$. L-Kynurenine (Sigma-Aldrich, St. Louis, MO, USA) diluted in culture medium was used to prepare the standard curve. The concentrations of $\mathrm{PGE}_{2}$ and IL-10 were measured using commercially available kits-the Parameter kit (R\&D Systems, Minneapolis, MN) and human IL-10 Enzyme-Linked Immunosorbent Assay (Thermo Fischer; cat. no. 88-7104-88), respectively. All measurements were done in duplicates.

2.5. Blocking Experiments. To investigate the role of PGE2 and kynurenines in the immunomodulatory capacity of ASCs, specific inhibitors of these factors synthesis, i.e., $10^{-6} \mathrm{M}$ of indomethacin (Sigma-Aldrich, Germany) or $1 \mathrm{mM}$ of 1-methyl-tryptophan (1-MT, Sigma-Aldrich, Germany), respectively, were added at the beginning of the cell culture periods. The above concentrations were selected from literature searches of previous studies [32-36]. After 48 hours of ASCs preincubation with specific inhibitors, PHA-activated and CFSE-stained PBMCs were added to the culture. Next, 1-MT or indomethacin was added again. The cultures were incubated for 5 days at $37^{\circ} \mathrm{C}$ in a humidified atmosphere of $5 \% \mathrm{CO}_{2}$. At the end of the coculture, PBMCs were harvested for further cytometric analysis.

\subsection{Flow Cytometry Analysis}

2.6.1. Identification of T Cell Subsets. PBMCs harvested from cultures were resuspended in $50 \mu \mathrm{l}$ of FACS buffer and stained for $30 \mathrm{~min}$ on ice for respective membrane antigens using fluorochrome-conjugated monoclonal antibodies specific for human: CD4-APC-Cy7 (BD Pharmingen, San Diego, CA, USA) or CD8-PerCP (eBioscience, San Diego,
CA, USA). After the washing step, cells were acquired and analyzed using a FACSCanto cell cytometer and the Diva software. Appropriate isotype controls were used in all experiments.

2.6.2. Proliferation Assay. For proliferation assay, PBMCs were stained with carboxyfluorescein diacetate succinimidyl ester (CFSE) (Thermo Fisher Scientific, Massachusetts, MA, USA), then stimulated with PHA and cocultured with ASCs as described above. Cells harvested from cultures were analyzed by flow cytometry to identify proliferating and nonproliferating cells. To characterize cellular proliferation response, the percentage of proliferating cells, proliferation index (PI), and replication index (RI) was calculated as described elsewhere [37], using the following mathematical formulas:

$$
\mathrm{PI}=\frac{\sum_{1}^{i} i \times\left(N_{i} / 2^{i}\right)}{\sum_{1}^{i}\left(N_{i} / 2^{i}\right)} .
$$

Proliferation index is for responding cells, an average number of a division they have undergone; $\mathrm{Nis}$ the number of cells in the division, andiis the number of division.

$$
\mathrm{RI}=\frac{\sum_{1}^{i} N_{i}}{\sum_{1}^{i}\left(N_{i} / 2^{i}\right)} .
$$

Replication index is for responding cells, fold expansion over the culture time; $N$ is the number of cells in the division, andiis the number of division.

Exemplary histograms showing the proliferation of PHAstimulated PBMCs in various culture variants are shown in Figure 1S (supplementary materials).

2.7. Data Analyses. Data were analyzed using the GraphPad Prism software version 7. The Shapiro-Wilk test was used as a normality test. One-way analysis of variance (ANOVA) with repeated measures and post hoc Tukey test was used to assess the effect of untreated and TNF/IFN $\gamma$-treated ASCs on target cells, to compare contacting versus (vs.) noncontacting cocultures and allogeneic vs. autologous cocultures. The Mann-Whitney test was applied to analyze differences between HD/ASCs and AS/ASCs.

Parametric (Pearson's linear) and nonparametric (Spearman's rank) correlation tests were used to assess an association between analyzed parameters. Probability values less than 0.05 were considered significant.

\section{Results}

3.1. Patients. The patient cohort was heterogeneous concerning demographic and clinical data (Table 1 ). Ninety percent of patients were HLA-B27 positive, $40 \%$ of them had ocular symptoms (uveitis), and $10 \%$ had peripheral arthritis. They were mostly treated with nonsteroid anti-inflammatory drugs (NSAIDs), while application of nonbiologic diseasemodifying antirheumatic drugs (DMARDs) and glucocorticosteroids was less frequent. 
3.2. Inhibition of $T$ Cell Proliferation by ASCs. In control, separately cultured, PHA-treated PBMCs $\left(\mathrm{PBMCs}_{\mathrm{PHA}}\right)$, the majority of $\mathrm{CD}^{+}$and $\mathrm{CD}^{+} \mathrm{T}$ cells proliferated (mean \pm SEM $=88.7 \pm 1.6 \%$ and $81.9 \pm 2.4 \%$, respectively), but considerable PBMC donor-dependent variation was observed (Figures 1(a) and 1(d)). As showed in Figure $2 S$ in supplementary materials, also the degree of inhibition of proliferative response was determined by the individual specificity of the donors of PBMCs, because the same HD/ASCs or AS/ASC lines exerted nonidentical effects on $\mathrm{PBMCs}$ originated from different donors (compare donors no. 1 and no.2). Therefore, HD/ASC and AS/ASC activities were evaluated in the same experiments, using PBMCs from the same donors. In the presence of both untreated and TI-stimulated ASCs, the number of proliferating T cells of both subsets and the number of division per proliferating cell (PI) as well as fold expansion of these cells (RI) decreased significantly. Importantly, HD/ASCs and AS/ASCs exerted similar inhibitory effects (Figures $1(\mathrm{a})-1(\mathrm{f})$ ). In the cocultures with $\mathrm{HD} / \mathrm{ASC}$ and $\mathrm{HD} / \mathrm{ASCs}_{\mathrm{TI}}$ vs. AS/ASCs and $\mathrm{AS}_{\text {ASCs }} \mathrm{AI}_{\mathrm{TI}}$, the number of proliferating $\mathrm{CD}^{+}$cells was inhibited by $23.1 \pm 5.8 \%$ and $44.2 \pm 6.2 \%$ vs. $29.3 \pm 5.8 \%$ and $40.8 \pm 7.4 \%$, respectively, while the number of proliferating $\mathrm{CD}^{+}$cells was reduced by $14.3 \pm 4.6 \%$ and $40.3 \pm 7.7 \%$ vs. $29.4 \pm 5.7 \%$ and $34.9 \pm 6.2 \%$, respectively (mean \pm SEM; data not shown). There were no significant differences between the effects exerted by untreated and TI-treated AS/ASCs (Figures 1(a)-1(f)), while TI-treated HD/ASCs were more potent inhibitors of $\mathrm{T}$ cell proliferation than untreated HD/ASCs (Figures 1(a)-1(d) and 1(f)).

\subsection{Contribution of Cell-to-Cell Contact and Soluble Factors} to the Antiproliferative Effect of ASCs. In the coculture conditions allowing or preventing (transwell) direct cell-to-cell contact, untreated and TI-treated AS/ASCs similarly reduced proliferation of $\mathrm{CD}^{+}$(Figures 2(d)-2(f)) and $\mathrm{CD}^{+}$ (Figures 3(d)-3(f)) T cells, while the inhibitory effect of HD/ASCs was even more potent in transwell than cell-tocell contact cultures, and such differences were observed in the case of $\mathrm{CD}^{+}$(Figures 2(a)-2(c)) and $\mathrm{CD}^{+}$ (Figures 3(a)-3(c)) $\mathrm{T}$ cells. These results point to secretory factors as the critical mediators of ASCs triggered antiproliferative effects.

3.4. Upregulation of Kynurenines and $P G E_{2}$ in the Cocultures of ASCs with PBMCs. Untreated PBMCs produced little to moderate quantity of kynurenines which upon activation rose significantly (mean \pm SEM, $1.69 \pm 0.25$ vs. $2.56 \pm 0.32$ $\mu \mathrm{mol} / \mathrm{ml}, P=0.0011$ for untreated PBMCs vs. $\mathrm{PBMCs}_{\mathrm{PHA}}$ ). A similar, significant increase of $\mathrm{PGE}_{2}$ level was found as well (no secretion vs. $456.2 \pm 163 \mathrm{pg} / \mathrm{ml}, P=0.016$ for untreated PBMCs vs. $\left.\mathrm{PBMCs}_{\mathrm{PHA}}\right)$. According to our previous findings, both $\mathrm{HD} / \mathrm{ASCs}$ and AS/ASCs secrete kynurenines $(2.5 \pm 0.3$ vs. $0.4 \pm 0.2 \mu \mathrm{mol} / \mathrm{ml}, P<0.0001)$ and $\mathrm{PGE}_{2}(134 \pm 27$ vs. $357 \pm 120 \mathrm{pg} / \mathrm{ml}, P=0.35)$ spontaneously, and the release of these mediators increases upon TI pretreatment to the levels lower to similar to that found in present coculture experiments (kynurenines $4.3 \pm 0.4$ vs. $0.8 \pm 0.3 \mu \mathrm{mol} / \mathrm{ml}, P<0.0001 ; \mathrm{PGE}_{2} 315 \pm 61$ vs. $811 \pm 246$ $\mathrm{pg} / \mathrm{ml}, P=0.23$ ) [24]. However, these indicative data can not be referred directly to present coculture conditions, because ASCs originated from other donors. Compared with separately cultured $\mathrm{PBMCs}_{\mathrm{PHA}}$, in the cocultures of these cells with both untreated and TI-stimulated HD/ASCs and AS/ASCs, significant increases of kynurenines and $\mathrm{PGE}_{2}$ production were observed (Figures 4(a) and 4(d)). In comparison to untreated ASCs, the addition of TI-treated HD/ASCs triggered the significantly higher generation of kynurenines (a similar tendency was noticed for $\mathrm{PGE}_{2}$ secretion), while in the presence of TI-treated AS/ASCs only higher release of $\mathrm{PGE}_{2}$ was found. However, no significant differences between the magnitude of kynurenines and $\mathrm{PGE}_{2}$ elevation in the presence of HD/ASCs versus AS/ASCs were found. By contrast, in the same culture conditions secretion of IL-10 did not rise (Figure 3S).

\subsection{Contribution of Cell-to-Cell Contact and Soluble Factors} to Upregulation of Kynurenines and PGE $E_{2}$ by ASCs. The elevation of kynurenines and $\mathrm{PGE}_{2}$ production by untreated HD/ASCs and AS/ASCs was significantly higher in transwell than cell-to-cell contact cocultures with $\mathrm{PBMCs}_{\mathrm{PHA}}$, and a similar tendency was observed in cocultures containing TItreated ASCs (Figures 4(b), 4(c), 4(e), and 4(f), respectively), suggesting an important role of soluble factors in upregulation of both kynurenines and $\mathrm{PGE}_{2}$.

3.6. Association of the Secretion of Soluble Factors with the Antiproliferative Effect of ASCs. As shown in Figure 5, in the cocultures of PBMCs ${ }_{\mathrm{PHA}}$ with TI-treated HD/ASCs and AS/ASCs, the concentration of kynurenines inversely correlated with the percentage of proliferating $\mathrm{CD}_{4}^{+}(\mathrm{a}, \mathrm{e})$ and $\mathrm{CD}^{+}(\mathrm{b}, \mathrm{f}) \mathrm{T}$ cells. A similar relationship was observed for untreated AS/ASCs (Figure (Figure 4S, panels E, F). However, in the case of HD/ASCs, it was statistically significant only for $\mathrm{CD}^{+}$, but not $\mathrm{CD} 4^{+}$, cell proliferation (Figure 4S, panels $\mathrm{B}$ and $\mathrm{A}$, respectively). A negative correlation between the percentage of proliferating $\mathrm{CD} 4^{+}$ and $\mathrm{CD}^{+} \mathrm{T}$ cells and $\mathrm{PGE}_{2}$ secretion was also found, but due to a small number of experiments, it does not always reached its statistical significance. Nevertheless, it was noticed only in the presence of TI-treated (Figures 5(c), 5(d), and 5(h); the similar trend in $(\mathrm{g}))$ but not untreated (Figure 4S, panels C, D, G, H) ASCs. By contrast, secretion of IL-10 failed to show an inverse correlation with the number of proliferating $\mathrm{T}$ cells (Figure $5 \mathrm{~S}$ ), and in the cocultures of PBMCs $s_{\mathrm{PHA}}$ with $\mathrm{HD} / \mathrm{ASCs}_{\mathrm{TI}}$ secretion of IL10 correlated even positively with the number of proliferating $\mathrm{CD}^{+} \mathrm{T}$ cells (Figure $5 \mathrm{~S}$, panel $\mathrm{C}$ ). These results point out kynurenines and $\mathrm{PGE}_{2}$, but not IL-10, as likely mediators of the antiproliferative capacity of ASCs. To verify this, we performed blocking experiments in which selective inhibitors of kynurenines (1-MT) and $\mathrm{PGE}_{2}$ (indomethacin) generation were used (Figures 6 and 7).

Both 1-MT and indomethacin partly, but significantly, abolished the antiproliferative effect of TI-treated HD/ASCs on $\mathrm{CD}^{+}$and $\mathrm{CD}^{+}$cells, increasing the number of proliferating cells as well as proliferation and replication indices. By contrast, applied inhibitors failed to reverse the weak 


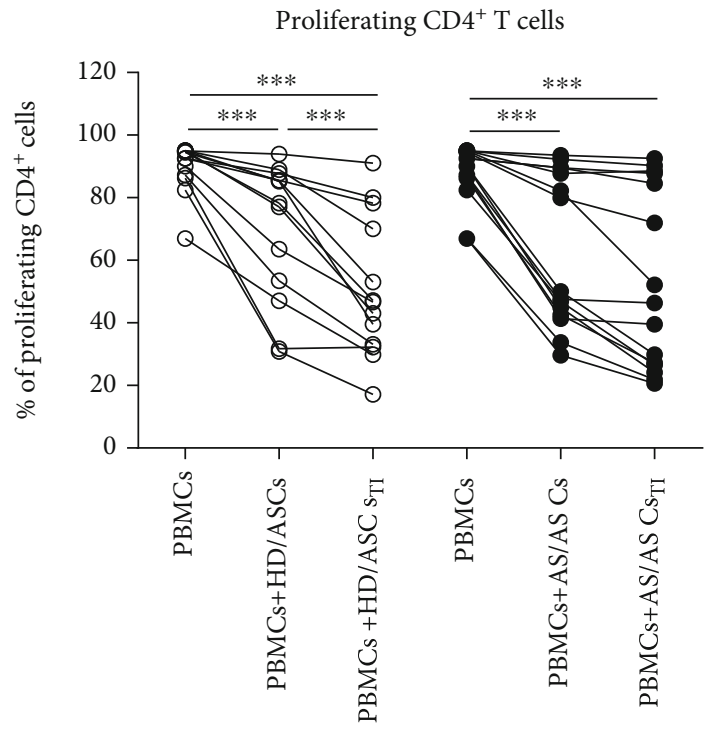

(a)

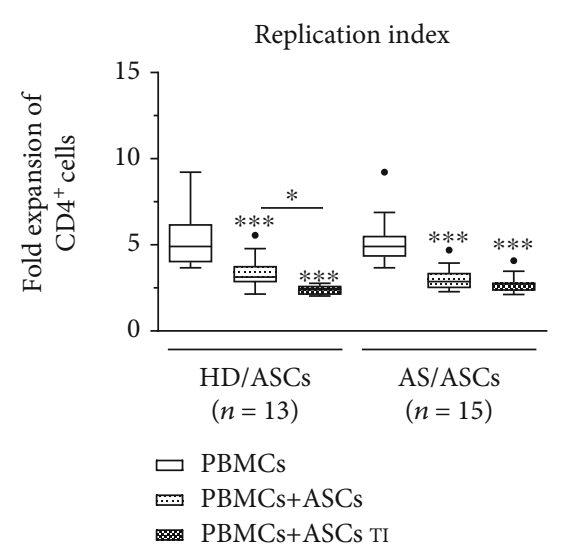

(c)

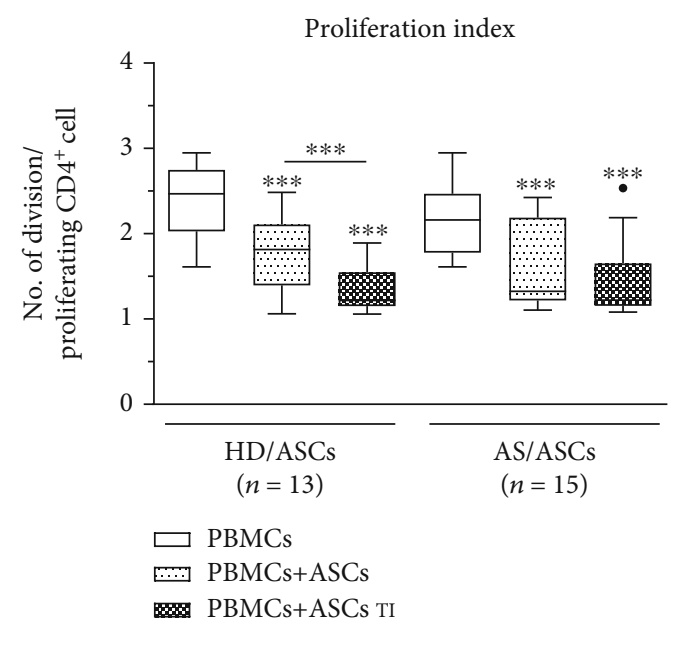

(b)

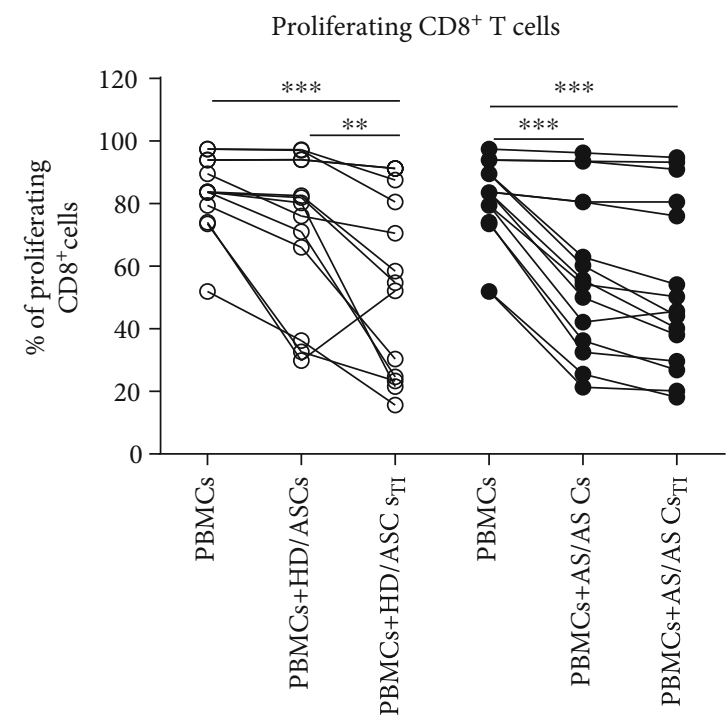

(d)

Figure 1: Continued. 


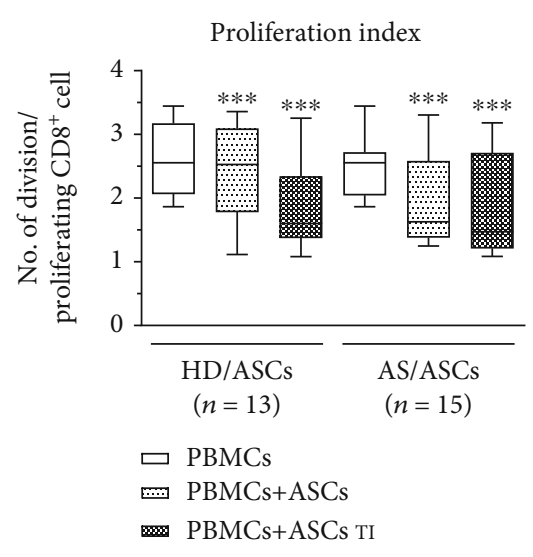

(e)

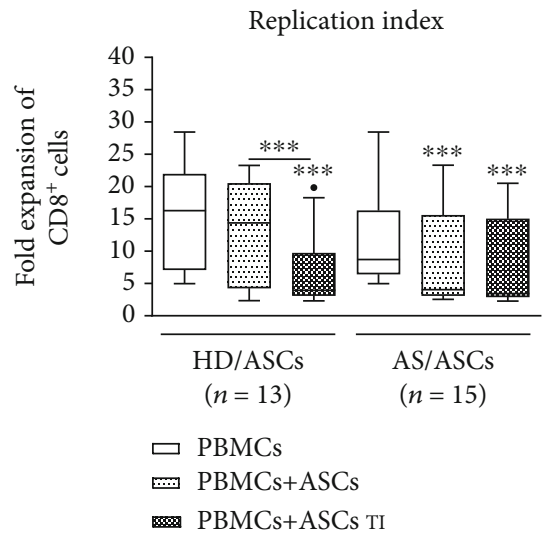

(f)

FIGURE 1: Inhibition of T cell proliferation by ASCs of healthy donors (HD) and AS patients. Peripheral blood mononuclear cells (PBMCs) obtained from 9 healthy donors (HD) were stimulated with PHA and cultured alone (control) or cocultured for 5 days with either untreated or TNF + IFN $\gamma$ - (TI-) stimulated ASCs from 5 HD (HD/ASCs) or 10 AS patients (AS/ASCs). The proliferation of CD4 ${ }^{+}(\mathrm{a}-\mathrm{c})$ and CD8 ${ }^{+}(\mathrm{d}-\mathrm{f})$ $\mathrm{T}$ cells was analyzed by flow cytometry. Data are the results of the indicated number of experiments $(n)$. (a, d) Lines between points identify cultures containing the same combination of ASCs and PBMCs. (b-f) Results are expressed as the median (horizontal line) with interquartile range (IQR, box), lower and upper whiskers (data within $3 / 2 \times \mathrm{IQR}$ ) and outliers (points) (Tukey's box). ${ }^{*} P=0.05-0.01,{ }^{* *} P=0.01-0.001$, and ${ }^{* * *} P=0.001-0.0001$ for intragroup comparisons (cell cocultures vs. control separate cultures and as indicated). The intergroup (HD vs. AS) differences were statistically insignificant.

inhibitory effect exerted by untreated HD/ASCs on the proliferation of these cells (Figures 6(a)-6(c) and Figures 7(a)$7(\mathrm{c})$, respectively). As for the antiproliferative capacity of AS/ASCs, 1-MT counteracted the effects of TI-treated cells on $\mathrm{CD}^{+}$(Figures 6(d)-6(f)) and $\mathrm{CD}^{+}$(Figures 7(d)-7(f)) $\mathrm{T}$ lymphocytes by increasing significantly the number of proliferating $\mathrm{T}$ cells and/or proliferation and replication indices, respectively. Indomethacin, in turn, almost completely reverted the number of proliferating $\mathrm{CD}^{+}$and $\mathrm{CD}^{+}$cells which was significantly reduced in the presence of both TItreated and untreated AS/ASCs.

\subsection{Immunoregulatory Effects of AS/ASCs toward Autologous} PBMCs. Comparison of simultaneously performed cocultures of untreated and TI-treated AS/ASCs with allogeneic

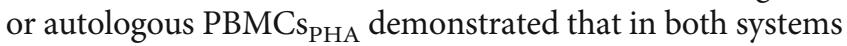
AS/ASCs exerted similar antiproliferative effects on $\mathrm{CD} 4^{+}$ and $\mathrm{CD}^{+} \mathrm{T}$ cells (Figures 8(a)-8(f)), as well as elevated the concentrations of kynurenines and $\mathrm{PGE}_{2}$ to similar levels (Figures 8(g) and 8(h), respectively). Besides, TI-treated AS/ASCs triggered an even significantly higher increase of kynurenines in the cocultures of autologous than allogeneic PBMCs (Figure 8(g)).

\section{Discussion}

It is well established that MSCs play a significant immunoregulatory role by damping down the activation of various immune cells, including $\mathrm{T}$ lymphocytes, monocytes/macrophages, and dendritic cells. Among numerous regulatory activities, immunosuppressive effects of MSCs on T cell proliferation have been confirmed both in vitro and in vivo conditions [10-14, 32, 38]. In ankylosing spondylitis, T cell expansion, noticed locally and in the periphery, is thought to play a pathogenic role [4-9]. Importantly, BM-MSCs of
AS patients have some functional defects and are thought to contribute to pathological bone homeostasis [16-21]. It is worth noting that bone marrow is more prone to chronic inflammation than adipose tissue. All these observations may indicate a diminished therapeutic utility of autologous BM-MSCs in AS. Numerous data demonstrate that the immunomodulatory efficacy of MSCs from different tissue sources is not equal, and adipose tissue-derived MSCs (ASCs) have stronger immunosuppressive properties than BM-MSCs [14, 39]. Unfortunately, ASCs of AS patients have not been investigated in this regard. Our previous findings suggested that at least some AS/ASC properties may be changed, because of the reduced basal level of some surface molecules, i.e., CD90 and intracellular adhesion molecule 1 (ICAM-1) on AS/ASCs, impaired basal secretion of kynurenines and galectin- 3 by these cells, but the normal capability to regulate expression of activation markers on allogeneic $\mathrm{T}$ cells was revealed $[25,26]$. Therefore, in the present study, we have further evaluated the functionality of AS/ASCs by investigating their capability to control the proliferation of T cells, using HD/ASCs as the reference cell lines. Importantly, we found that in the allogeneic system both HD/ASCs and AS/ASCs inhibited the number of proliferating $\mathrm{CD}^{+}$ and $\mathrm{CD}^{+} \mathrm{T}$ cells with similar potency (Figures $1(\mathrm{a})$ and $1(d))$. Besides, a significant decrease in the number of divisions per proliferating $\mathrm{CD}^{+}$and $\mathrm{CD}^{+}$cell was also observed (Figures 1(b) and 1(e)), and consequently, both events resulted in the reduction of $\mathrm{T}$ cell expansion (Figures 1(c) and $1(\mathrm{f})$ ). Our results are consistent with the observations of others about MSC properties in general [10-14, 40, 41], but demonstrating AS/ASCs as the effective suppressors of the proliferation of allogeneic $\mathrm{CD} 4^{+}$and $\mathrm{CD} 8^{+} \mathrm{T}$ cells is a new finding.

To provide successful immunomodulation, MSCs employ direct cell-to-cell interactions and soluble factors 


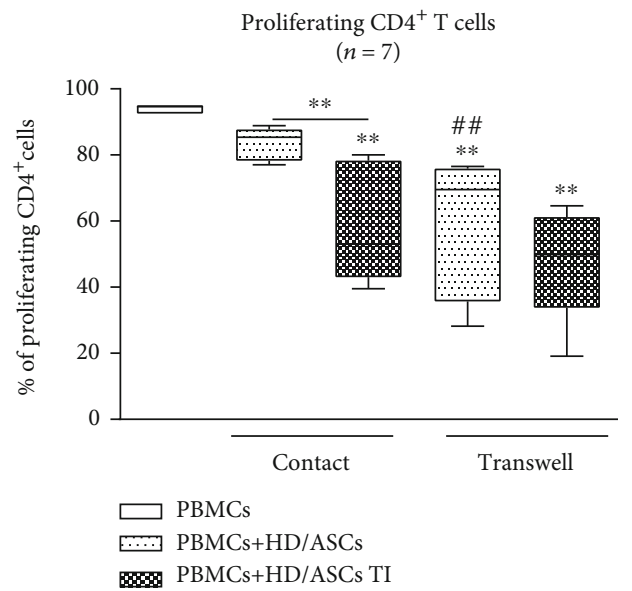

(a)

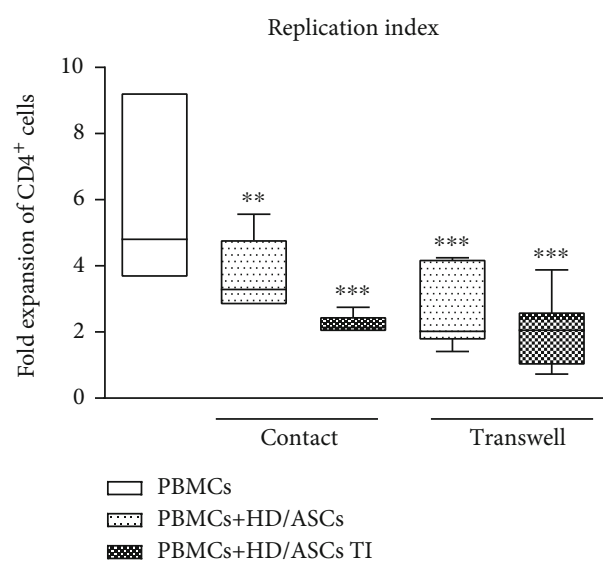

(c)

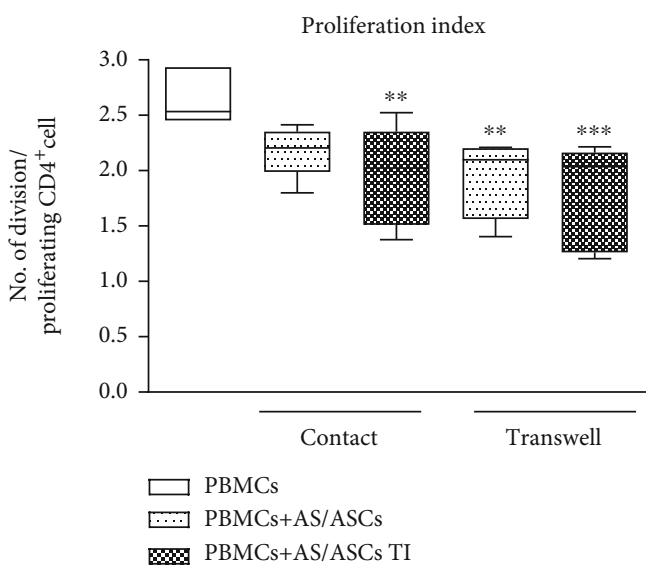

(e)

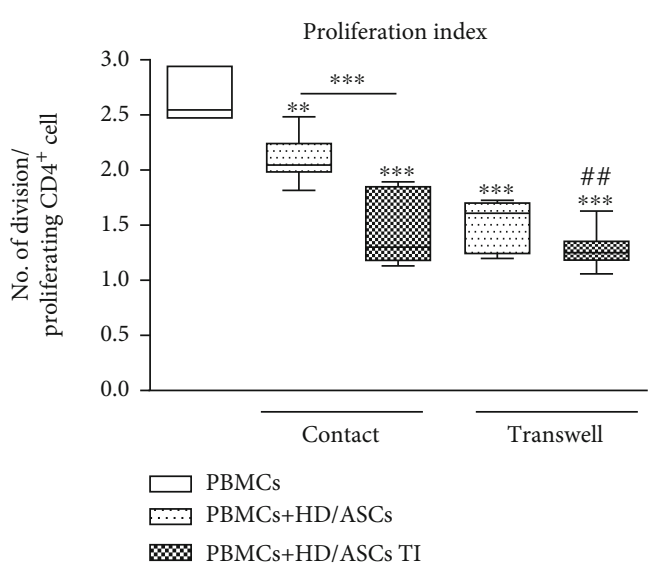

(b)

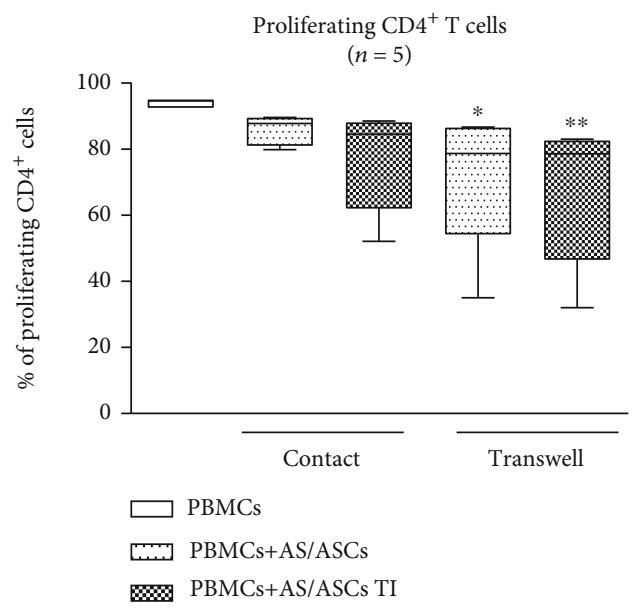

(d)

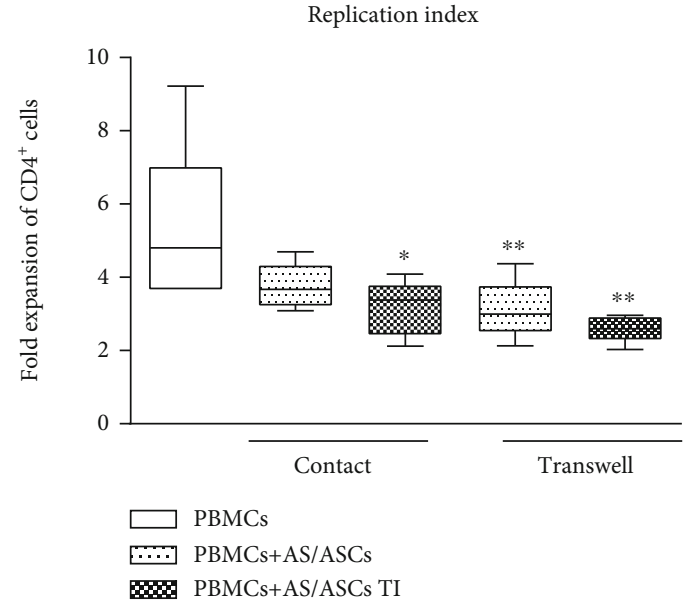

(f)

FIGURE 2: Comparison of ASC inhibitory effects on $\mathrm{CD}^{+} \mathrm{T}$ cell proliferation in contact and transwell cocultures. PBMCs, isolated from 3 healthy blood donors and activated with PHA, were cultured separately (control) or cocultured with ASCs from 4 healthy donors (HD/ASCs) or 5 AS patients (AS/ASCs) in conditions allowing direct cell contact or in a transwell system. Untreated and TNF + IFN $\gamma$ - (TI-) treated ASCs were used. The proliferation of $\mathrm{CD}^{+} \mathrm{T}$ cells was analyzed by flow cytometry. Data are the results of the indicated number of experiments $(n)$ and are shown as the Tukey's boxes. ${ }^{*} P=0.05-0.01,{ }^{* *} P=0.01-0.001$, and ${ }^{* * *} P=0.001-0.0001$ for comparison of cell cocultures vs. control separate cultures and as indicated. ${ }^{\# \#} P=0.01-0.001$ for comparison of contact vs. transwell cocultures. 
Proliferating $\mathrm{CD}^{+}$cells

$(n=7)$

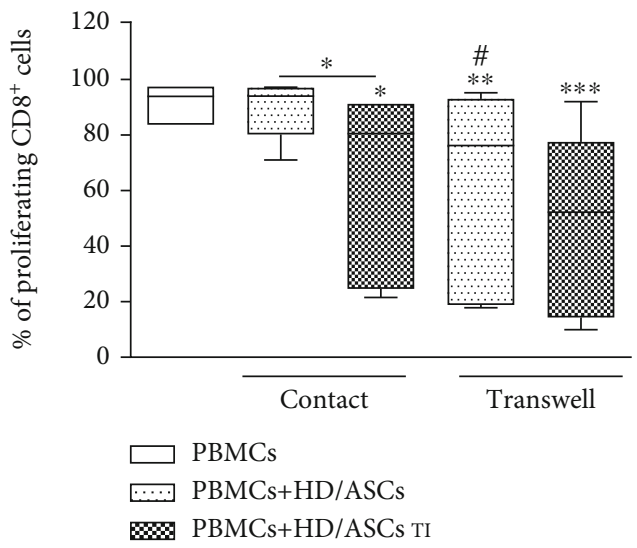

(a)

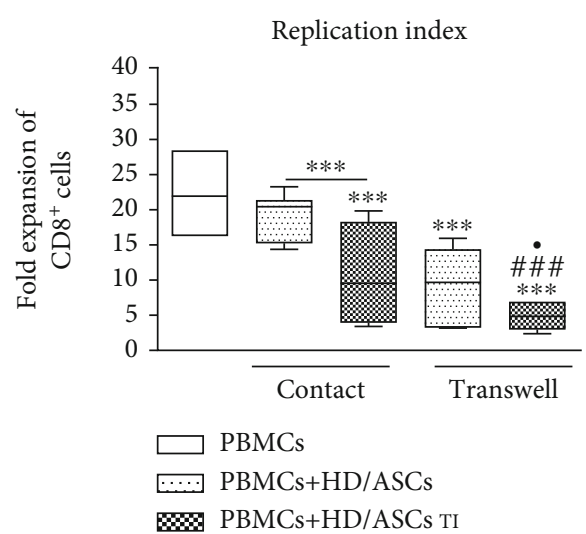

(c)

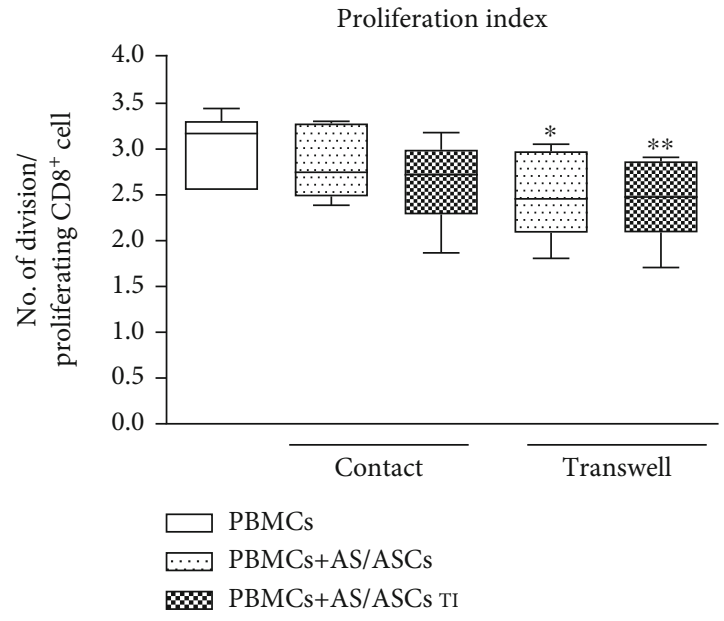

(e)

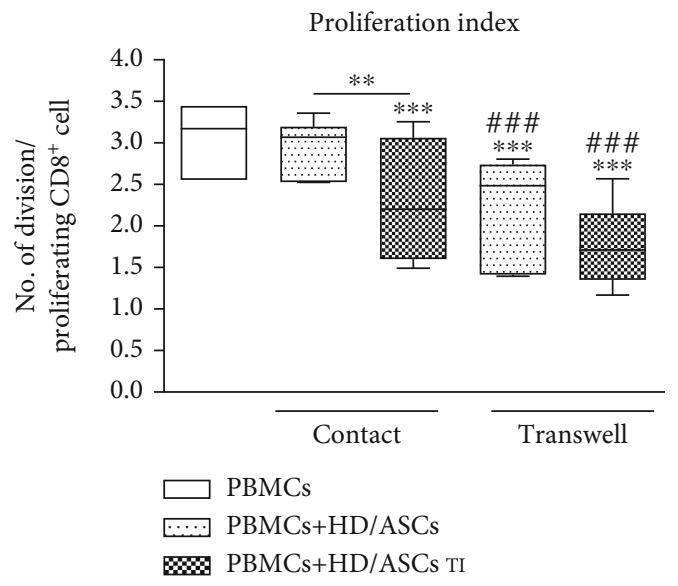

(b)

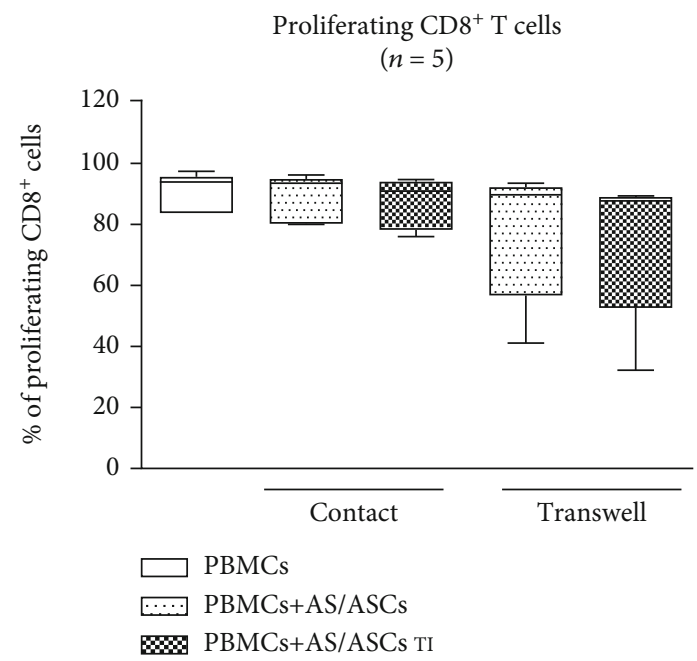

(d)

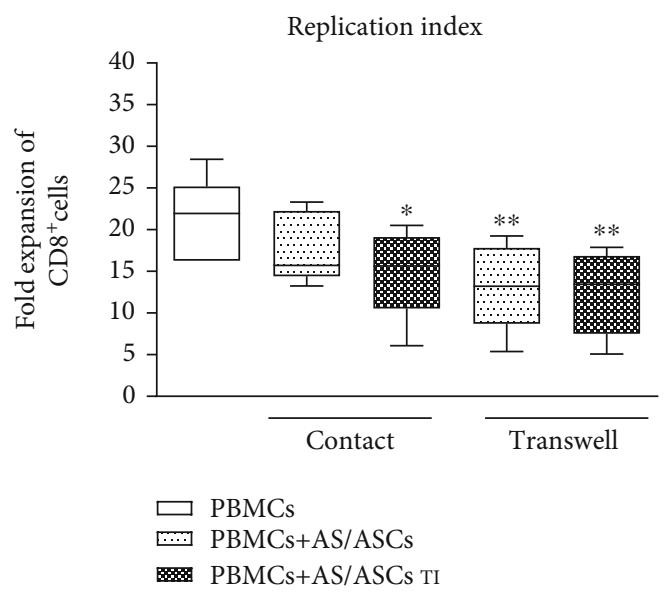

(f)

FIGURE 3: Comparison of ASC inhibitory effects on $\mathrm{CD} 8^{+} \mathrm{T}$ cell proliferation in contact and transwell cocultures. Cell origin and culture conditions as in Figure 2, except that CD8+ T cells were analyzed. ${ }^{*} P=0.05-0.01,{ }^{* *} P=0.01-0.001$, and ${ }^{* * *} P=0.001-0.0001$ for comparison of cell cocultures vs. control separate cultures and as indicated. ${ }^{\#} P=0.05-0.01$ and ${ }^{\# \# \#} P=0.001-0.0001$ for comparison of contact vs. transwell cultures. 


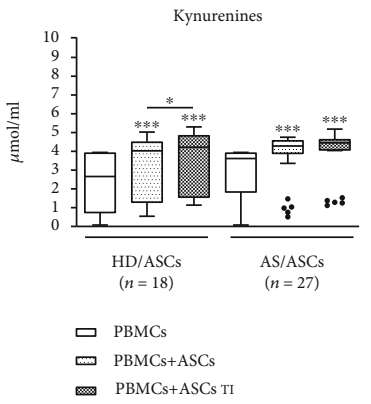

(a)

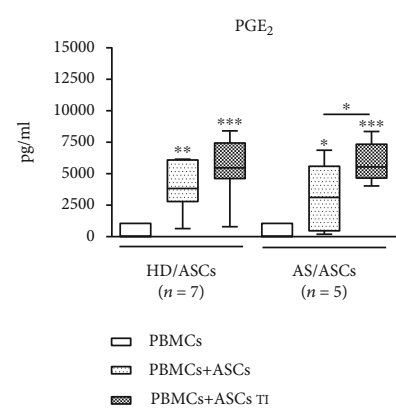

(d)

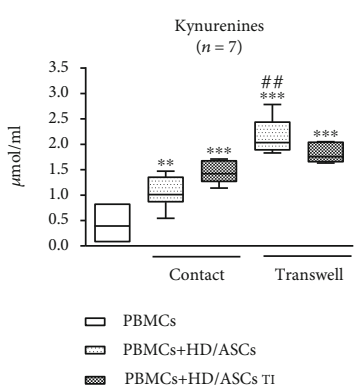

(b)

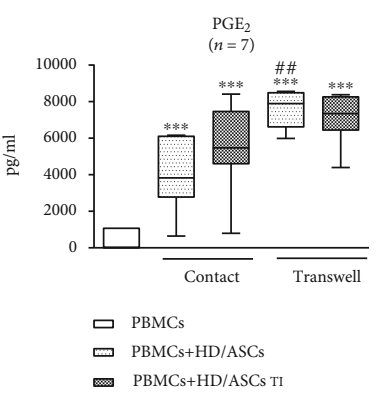

(e)

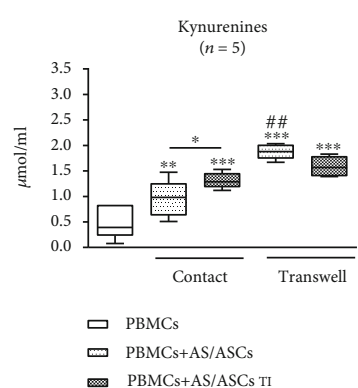

(c)

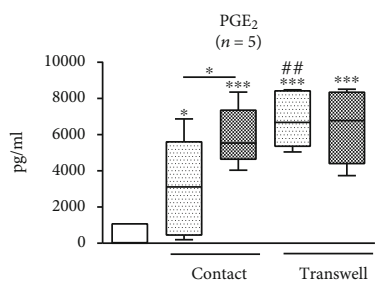

口 PBMCs

DBMCS+AS/ASCs

PBMCs+AS/ASCs T

(f)

FIGURE 4: Upregulation of kynurenines and prostaglandin $\mathrm{E}_{2}\left(\mathrm{PGE}_{2}\right)$ synthesis in the contacting and noncontacting cocultures of PBMCs with ASCs. Cells were prepared and cocultured as described in Figures 1(a) and 1(d) and Figures 2(b), 2(c), 2(e), and 2(f). PBMCs were isolated from peripheral blood of 11 (a) or 5-7 (b-e) healthy blood donors. Five HD/ASC lines and AS/ASCs obtained from 12 (a) or 5-7 (b-e) patients were used. The concentrations of kynurenines and $\mathrm{PGE}_{2}$ in culture supernatants were measured as described in Material and Methods. Data are shown as the Tukey's boxes; the number of performed experiments $(n)$ is shown. ${ }^{*} P=0.05-0.01,{ }^{* *} P=0.01-0.001$, and ${ }^{* * *} P=0.001-0.0001$ for comparison of cell cocultures vs. control separate cultures and as indicated. ${ }^{\# \#} P=0.01-0.001$ and ${ }^{\# \# \#} P=0.001-0.0001$ for comparison of contact vs. transwell cultures.

$[10,11,14,42,43]$. Similar to other reports [34, 44], we observed that the antiproliferative effect of HD/ASCs and AS/ASCs on both $\mathrm{CD}^{+}$and $\mathrm{CD}^{+} \mathrm{T}$ cells was mediated mostly by soluble factors (Figures 2 and 3). Further experiments identified kynurenines and $\mathrm{PGE}_{2}$ as critical contributors to the antiproliferative action of ASCs of both healthy donors and AS patients. First, we found that the concentrations of kynurenines and $\mathrm{PGE}_{2}$ (Figures 4(a) and 4(d)), but not anti-inflammatory cytokine-IL-10 (Figure 3S), rose significantly in the cocultures of PBMCs ${ }_{\mathrm{PHA}}$ with untreated as well as TI-stimulated HD/ASCs and AS/ASCs. Secondly, in the presence of TI preconditioned HD/ASCs and AS/ASCs, the concentrations of both factors, especially kynurenines, inversely correlated with the number of proliferating $\mathrm{CD}^{+}$and $\mathrm{CD}^{+}$cells (Figure 5), while no such association was found in the case of IL-10 (Figure 5S). Finally, the antiproliferative impact of HD/ASCs and AS/ASCs was partly, but significantly, abolished by selective inhibition of kynurenine and $\mathrm{PGE}_{2}$ generation (Figures 6 and 7). Our observations are consistent with other reports proving the most critical role of the kynurenine pathway for ASC inhibition of $\mathrm{T}$ cell proliferation in humans $[32,44,45]$. In this pathway, indoleamine 2,3-dioxygenase (IDO) catabolizes the essential amino acid tryptophan (Trp), resulting in local Trp deprivation and kynurenine generation that eventually lead to suppression of $\mathrm{T}$ cell proliferation, these cell apoptosis and formation of Treg cells $[46,47]$. The kynurenine pathway can be blocked by a Trp analog, 1-methyl-tryptophan (1-MT) which binds to the ferrous IDO complex but, due to the additional methyl group, cannot be catalytically converted to kynurenines [48]. Similar to the kynurenine pathway, also PGE2 was reported to mediate the antiproliferative effects of various types of MSCs on T cells [49-51]. Prostaglandin $\mathrm{E}_{2}$, one of the most potent members of the prostaglandin family, is known to regulate a multitude of events in $\mathrm{T}$ cell activation, including cell cycle arrest [52]. Like other prostanoids, $\mathrm{PGE}_{2}$ is synthesized from arachidonic acid on a metabolic pathway dependent on the enzymatic activity of cyclooxygenase (COX) isoenzymes, mainly COX1 and COX-2 [53]. Indomethacin, a nonsteroidal antiinflammatory drug, is a nonselective inhibitor of COX-1 and COX-2 activity and, consequently, an inhibitor of prostaglandin generation [51]. Interestingly, $\mathrm{PGE}_{2}$ was reported to induce IDO/kynurenine pathway in tolerogenic dendritic cells and to synergize with this pathway in the immunosuppression of NK cells by MSCs $[36,54]$. Thus, both pathways may cooperate in mediating the antiproliferative effects of ASCs on T cells as well. Based on the present results of blocking experiments and the correlation analysis and in line with other reports concerning various types of MSCs $[44,45,49,50]$, we point out kynurenines and $\mathrm{PGE}_{2}$ as the important mediators of antiproliferative action of not only HD/ASCs but also AS/ASCs. 


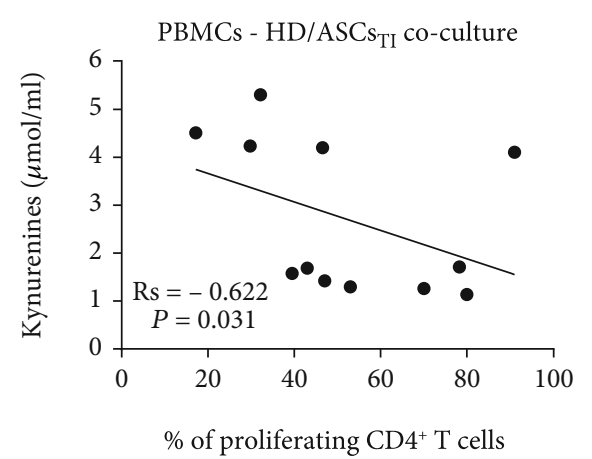

(a)

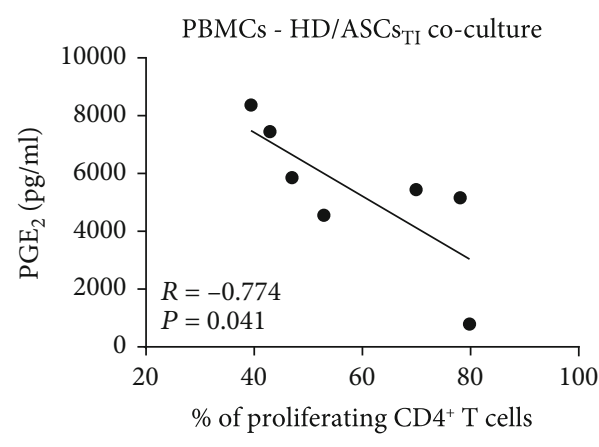

(c)

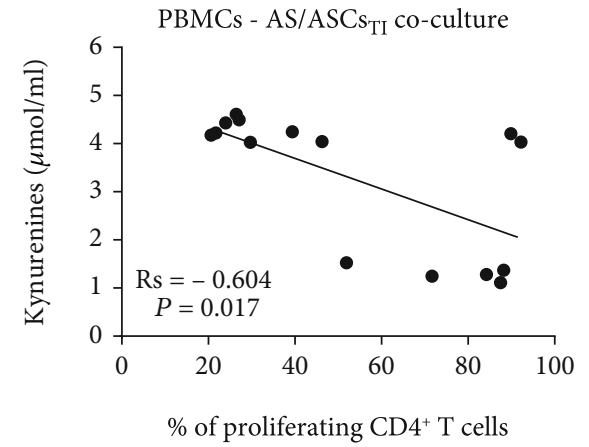

(e)

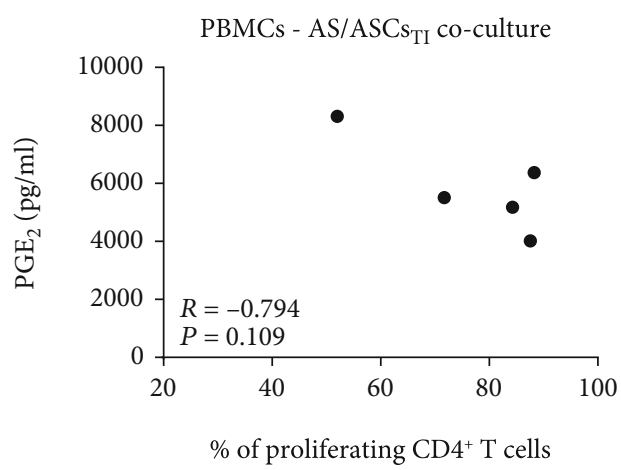

(g)

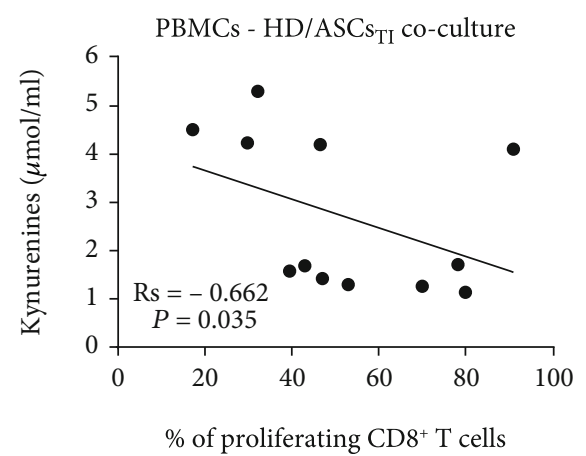

(b)

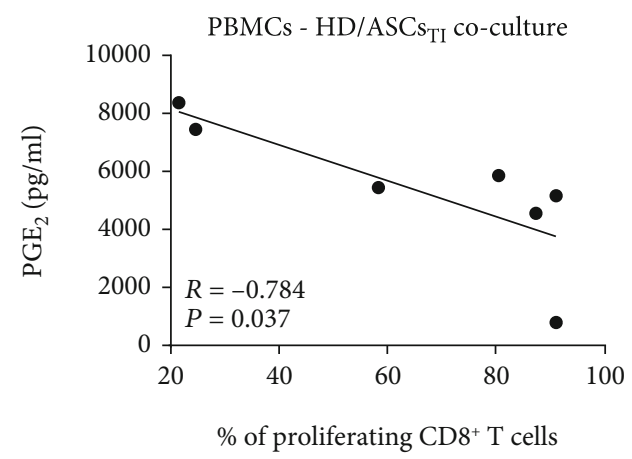

(d)

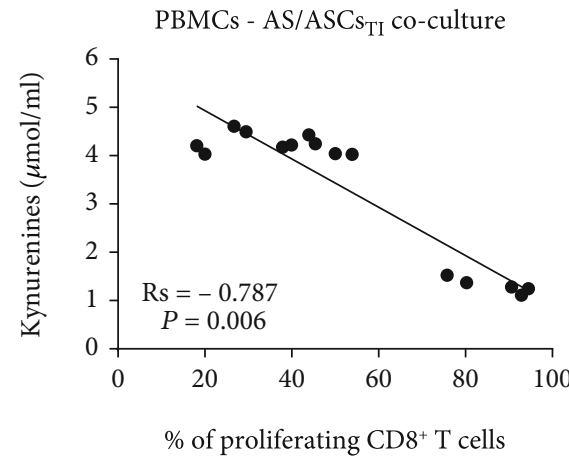

(f)

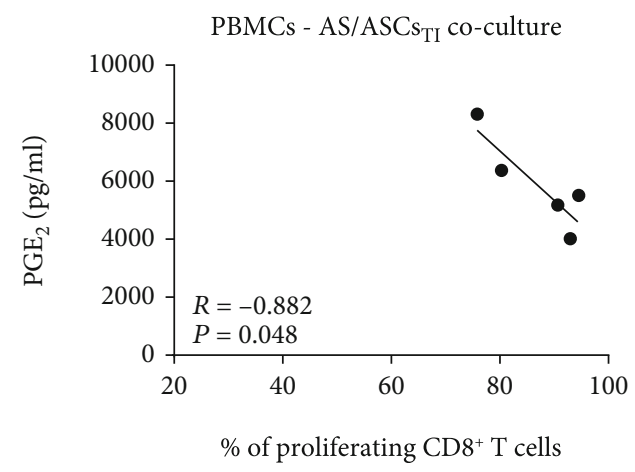

(h)

FIGURE 5: Correlation of kynurenines and $\mathrm{PGE}_{2}$ concentrations with the number of proliferating T cells. PBMCs stimulated with PHA were cocultured with TNF + IFN $\gamma$ - (TI-) treated ASCs from HD (a-d) and AS patients (e-h). The proliferation of CD4 ${ }^{+}(\mathrm{a}, \mathrm{c}, \mathrm{e}, \mathrm{g})$ and $\mathrm{CD} 8^{+}$ $(b, d, f, h)$ cells was evaluated, and the measurement of kynurenines and $\mathrm{PGE}_{2}$ concentrations was performed as described in Materials and Methods. Spearman's rank (Rs) (a, b, e, f) and Pearson's $(R)(\mathrm{c}, \mathrm{d}, \mathrm{g}, \mathrm{h}$ ) correlation coefficients and $P$ values are shown. Other explanations as in Figure 1. 


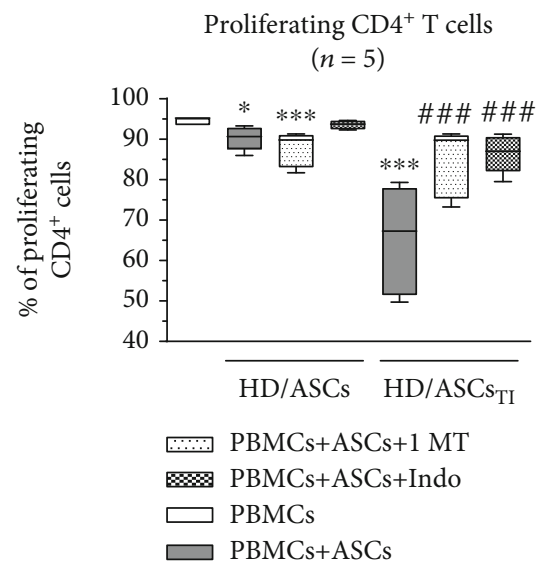

(a)

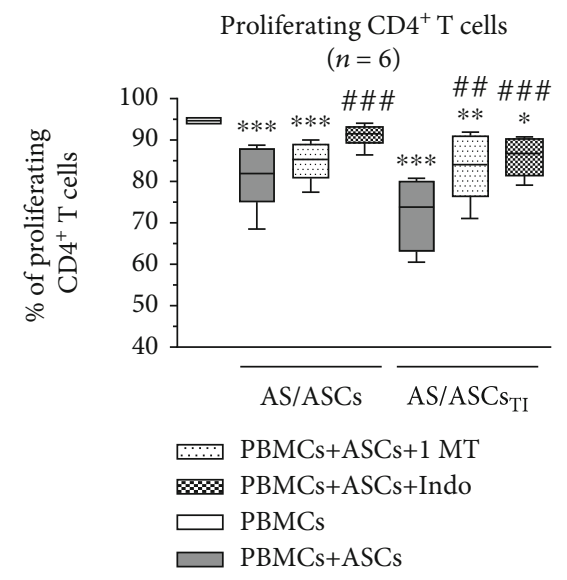

(d)

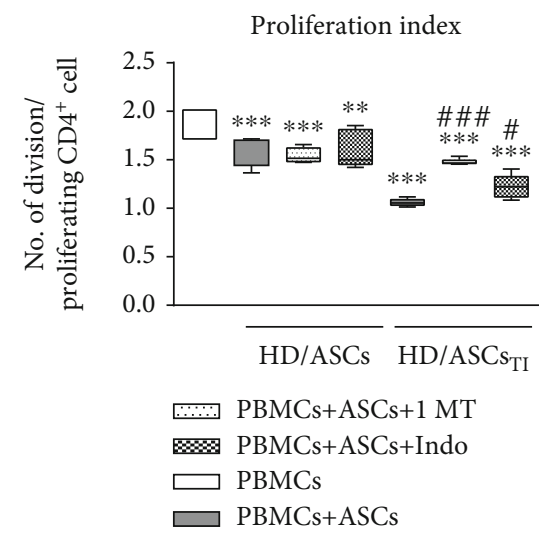

(b)

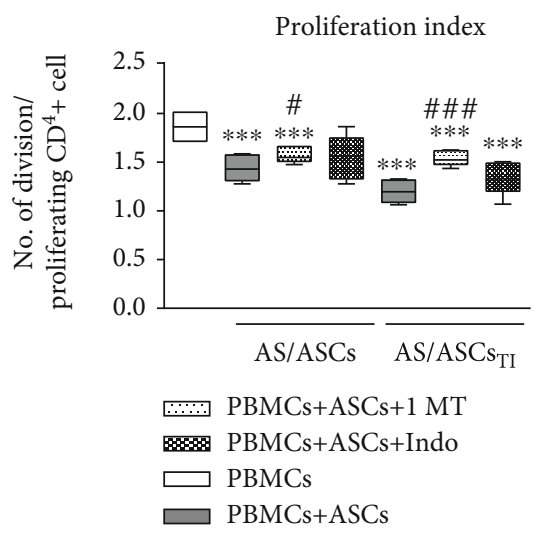

(e)

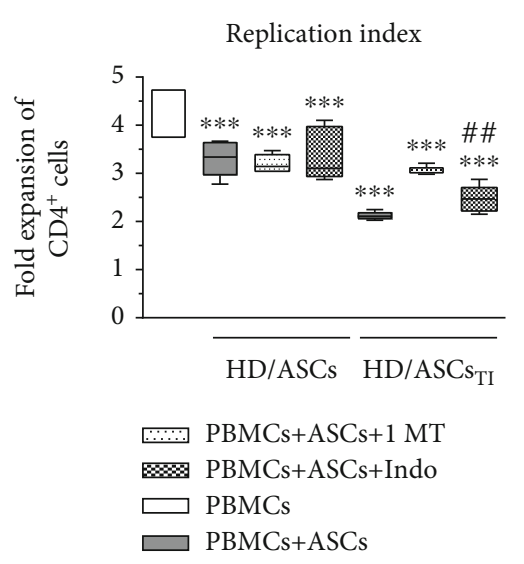

(c)

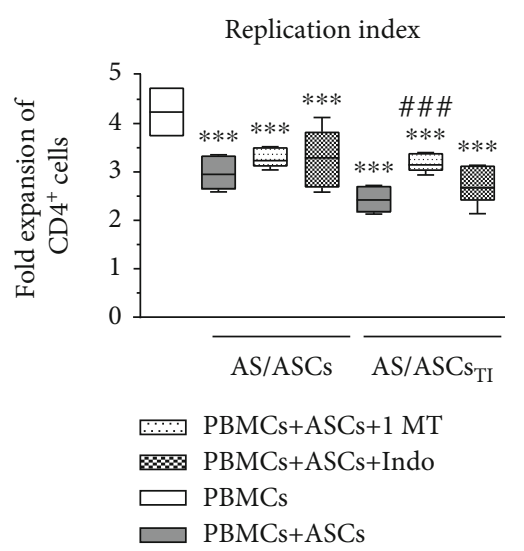

(f)

FIgURe 6: Selective inhibitors of kynurenines (1-MT) and $\mathrm{PGE}_{2}$ (indomethacin) synthesis counteract inhibitory effect of ASCs on proliferation of $\mathrm{CD}^{+} \mathrm{T}$ cells. Cell preparation and culture conditions as in Figure 1. The concentrations and time of cell treatment with 1-MT and indomethacin (Indo) are described in Materials and Methods. Data are shown as the Tukey's boxes; the number of performed experiments $(n)$ is shown. ${ }^{*} P=0.05-0.01,{ }^{* *} P=0.01-0.001$, and ${ }^{* * *} P=0.001-0.0001$ for comparison of cell cocultures vs. control separate cultures. ${ }^{\#} P=0.05-0.01$, ${ }^{\# \#} P=0.01-0.001$, and ${ }^{\# \#} P=0.001-0.0001$ for comparison of inhibitor treated vs. untreated cocultures. Other explanations as in Figure 1.

It should be clarified that because both $\mathrm{PBMCs}_{\mathrm{PHA}}$ and ASCs generated kynurenines and $\mathrm{PGE}_{2}$, in our experimental setting, both 1-MT and indomethacin were present during the whole period of cell coculture. As mentioned in Results (Section 3.4), the basal release of kynurenines and $\mathrm{PGE}_{2}$ by resting PBMCs was low, significantly elevated upon PHA-treatment, and further augmented in the presence of untreated and TI-treated HD/ASCs and AS/ASCs (Figures 4(a) and 4(d)). On the other hand, we have previously reported that, compared to HD/ASCs, the spontaneous generation of kynurenines by AS/ASCs is impaired, while the basal synthesis of $\mathrm{PGE}_{2}$ is normal. Also, we have noticed that these differences between AS/ASCs and HD/ASCs persist even upon TI stimulation which significantly elevates the generation of both kynurenines and $\mathrm{PGE}_{2}$ [26]. However, despite basal differences observed in separate cultures, present results show that in cocultures with target cells AS/ASCs are at least as productive as HD/ASCs (Figures 4(a) and 4(d)).
As mentioned before, the execution of MSCs immunomodulatory potential is a complex process involving various soluble mediators as well as direct MSCs interaction with immune cells. In contrast to the transwell system, in the cell contacting cocultures, the degree of $\mathrm{T}$ cell proliferation inhibition and the levels of immunosuppressive mediators result from complex and multidirectional interactions between MSCs and different types of cells in the PBMCs pool. Present results showed (Figures 2 and 3 ) that the inhibitory effect of HD/ASCs on T cell proliferation was weaker in cell contacting than transwell cocultures, implying that interactions of HD/ASCs with other cell types may counteract, and thus supervise, the antiproliferative effect of these cells. A similar tendency was observed in the case of AS/ASCs, but the differences were statistically insignificant, suggesting weaker control of these cells' activity. Providing prosurvival signals may likely contribute to this event. For example, it was reported that in PBMCs-ASCs, coculture T, B, and NK cells adhere to ASCs, and part of bound T cells is kept in an 


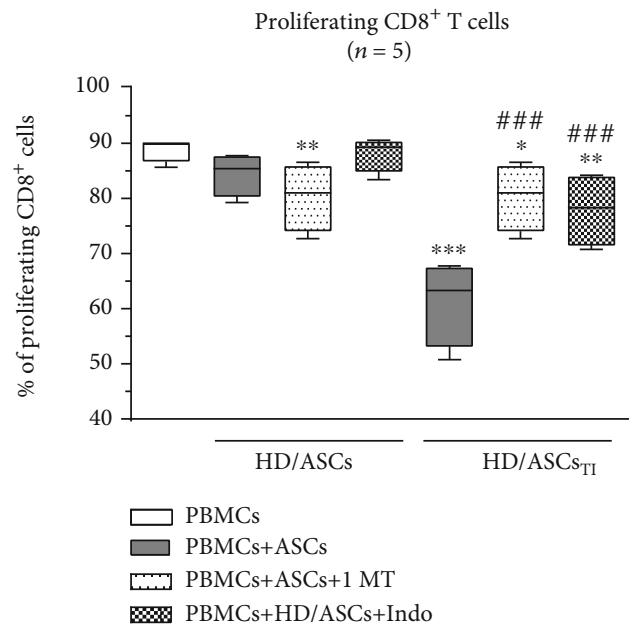

(a)

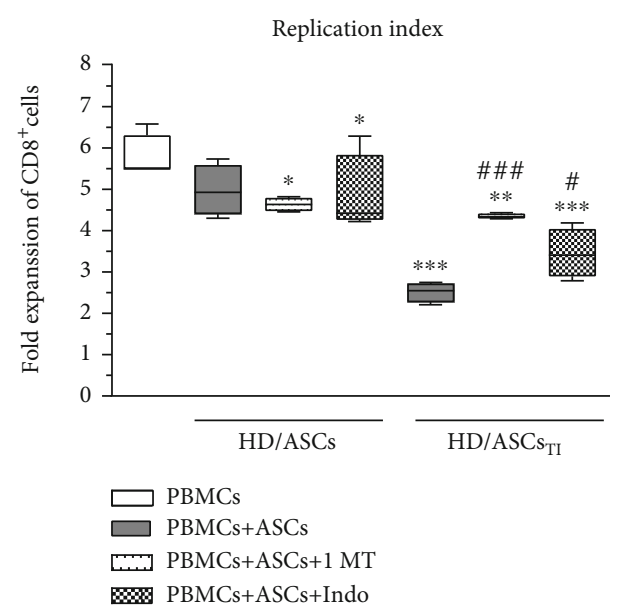

(c)

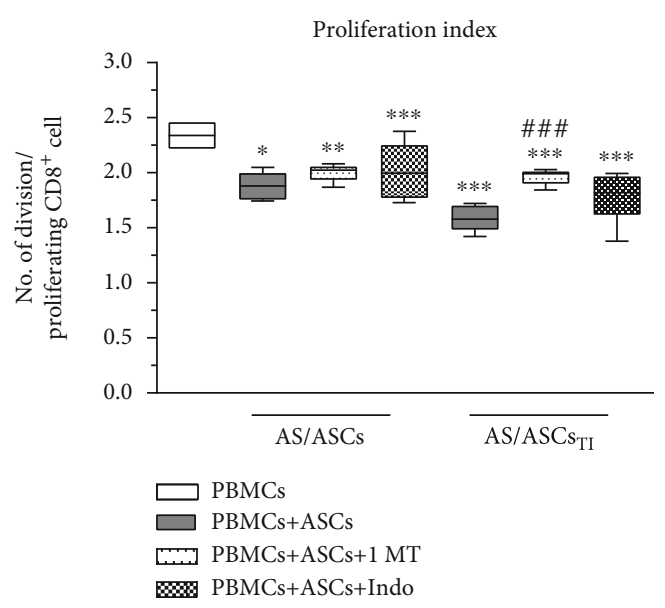

(e)

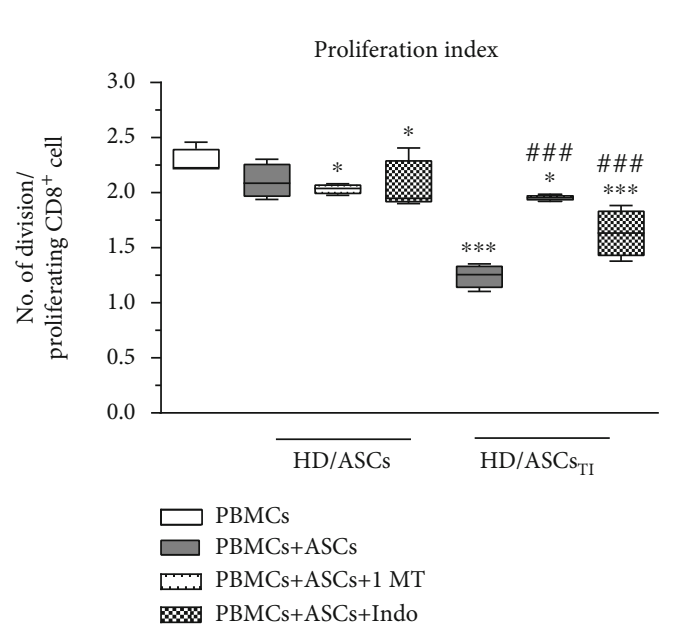

(b)

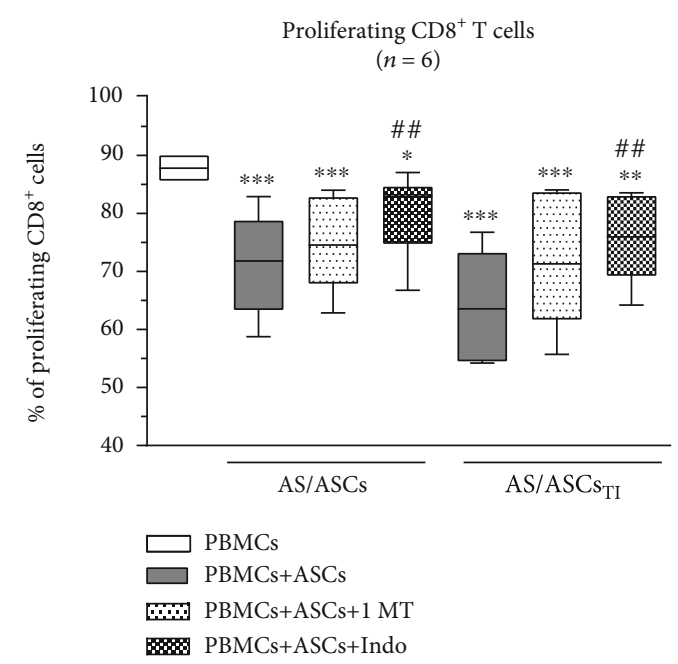

(d)

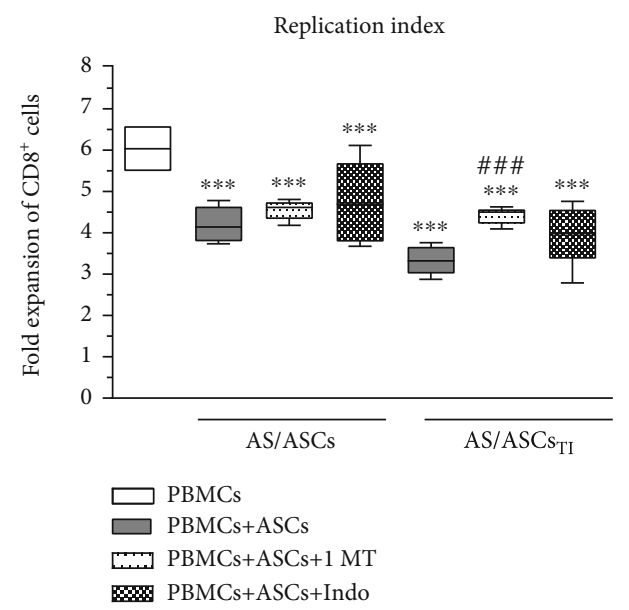

(f)

FIGURE 7: Selective inhibitors of kynurenines (1-MT) and $\mathrm{PGE}_{2}$ (indomethacin) synthesis counteract the inhibitory effect of ASCs on the proliferation of $\mathrm{CD}^{+} \mathrm{T}$ cells. Cell preparation, culture conditions, concentrations, and time of cell treatment with 1-MT and indomethacin (Indo) and other explanations as in Figure 6, except that CD8+ T cells were analyzed. 


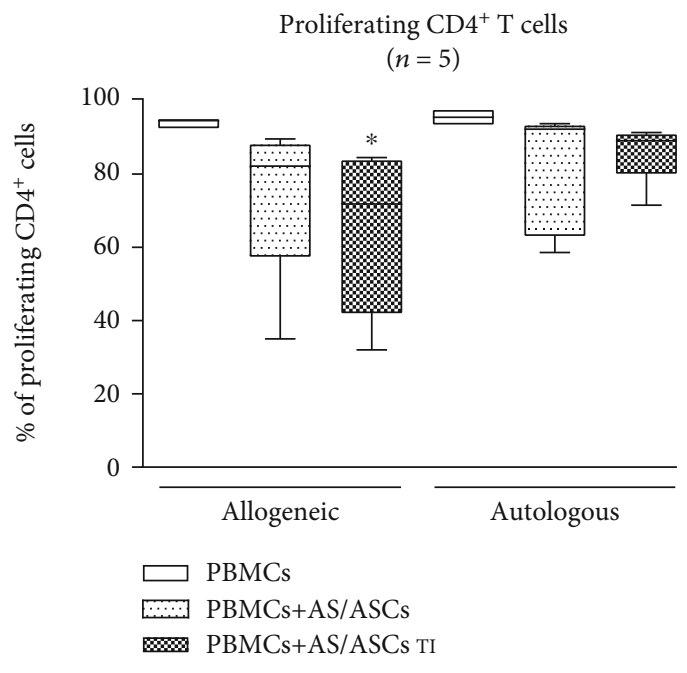

(a)

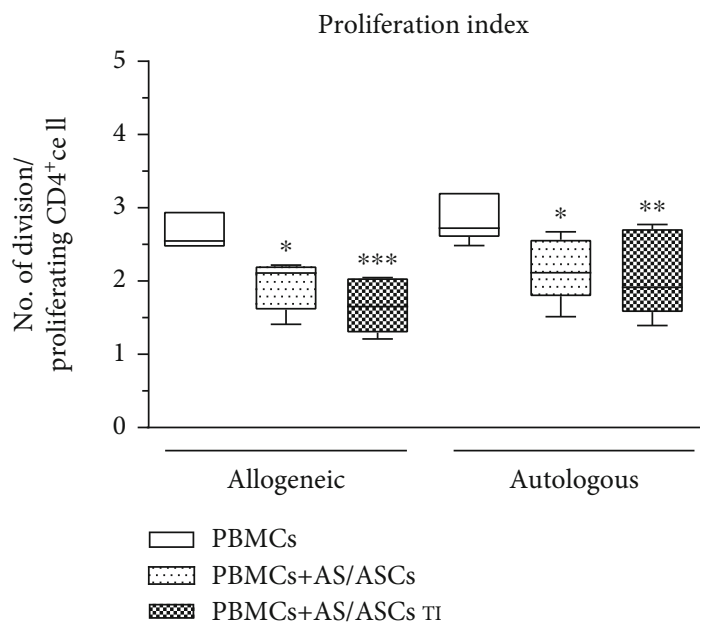

(c)

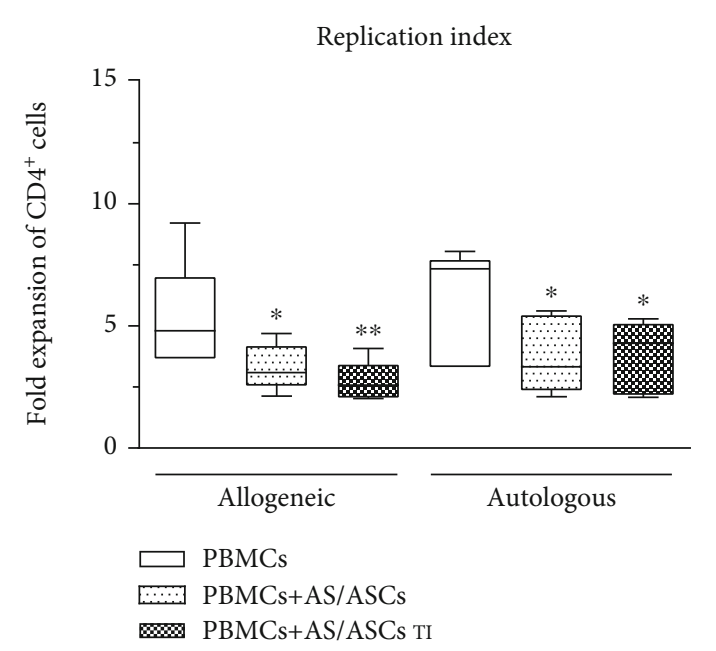

(e)

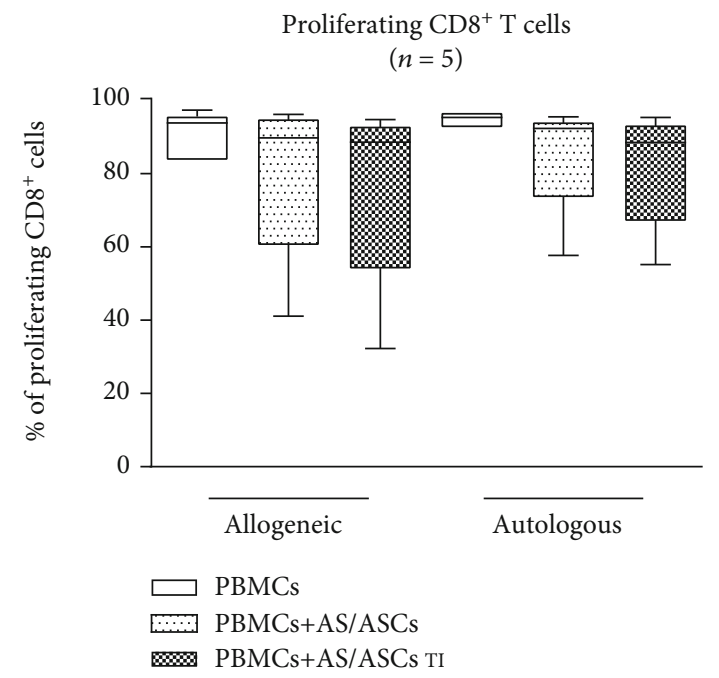

(b)

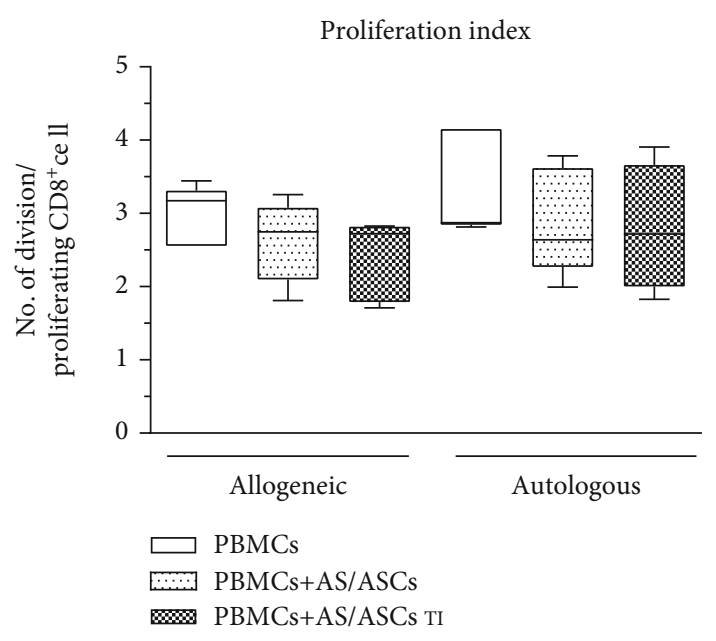

(d)

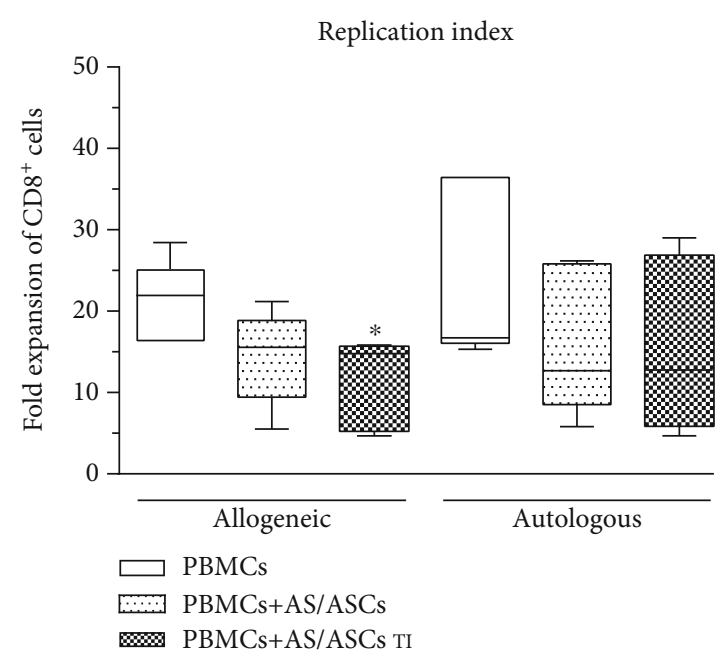

(f)

Figure 8: Continued. 


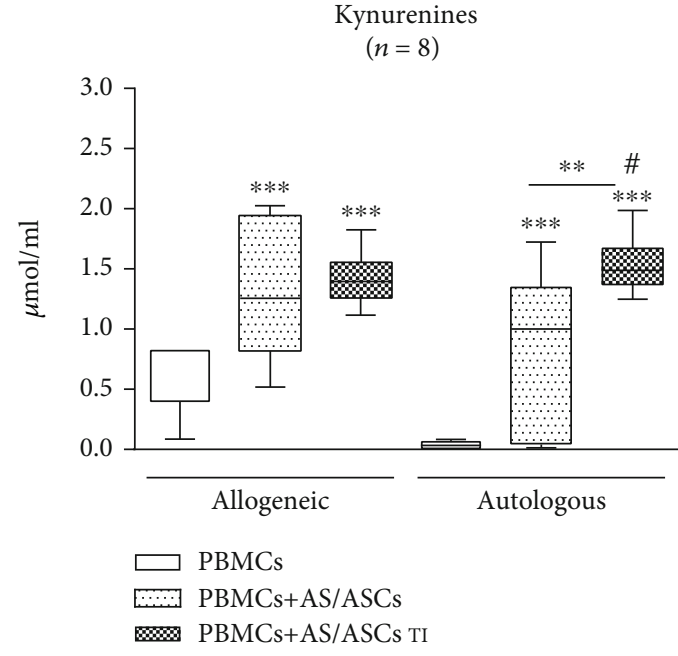

(g)

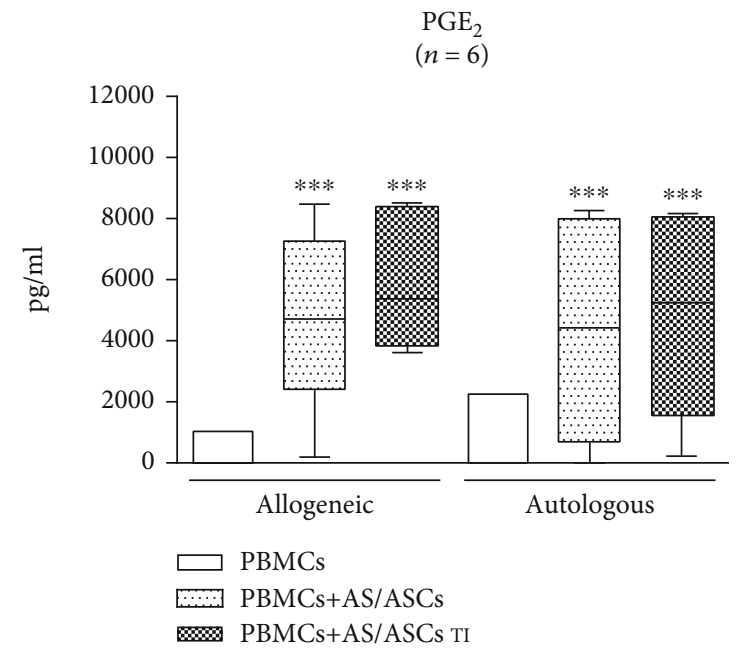

(h)

FIGURE 8: Comparison of immunomodulatory effects of AS/ASCs cocultured with allogeneic and autologous PBMCs. Cells were prepared and cocultured as described in Figure 1. Both allogeneic and autologous PHA-activated PBMCs were used as the target cells. Data are shown as the Tukey's boxes; the number of performed experiments $(n)$ is shown. ${ }^{*} P=0.05-0.01,{ }^{* *} P=0.01-0.001$, and ${ }^{* * *} P=0.001-0.0001$ for comparison of cell cocultures vs. control separate cultures and as indicated. ${ }^{\#} P=0.05-0.01$ for comparison of allogeneic vs. autologous cocultures.

activated, proliferative state. Interestingly, these cells express a high level of endoglin which switches transforming growth factor $\beta$ (TGF $\beta)$ signaling from anti- to proproliferative pathway [55]. Moreover, BM-MSCs were found to support $\mathrm{B}$ cell viability through direct cell contact, leading to upregulation of vascular endothelial growth factor (VEGF) which protects B cells against apoptosis [56]. In the cocultures of mononuclear cells with MSCs, even the density of MSC monolayer may generate prosurvival signals, because the decrease of monolayer density was followed by the dosedependent increase in lymphocyte proliferation [57]. Finally, the low expression level of various surface molecules that mediate cell-to-cell contact and contribute to the immunosuppressive properties of MSCs [58] may also affect the antiproliferative activity of MSCs, which was proven in the case of CD90 [59]. Although we found that, in general, HD/ASCs and AS/ASCs exerted comparable inhibitory effects on T cell proliferation and acted mostly via soluble factors, kynurenines and $\mathrm{PGE}_{2}$, some dissimilarities between these cell lines were also observed. First, TI-priming significantly enhanced the antiproliferative impact of HD/ASCs, but not AS/ASCs, on both $\mathrm{CD}^{+}$and $\mathrm{CD} 8^{+}$cells (Figure 1). Similarly, an inverse correlation between the concentration of kynurenines and the number of proliferating $\mathrm{CD} 4^{+}$and $\mathrm{CD} 8^{+}$cells was more evident in cocultures containing TI-licensed (Figures 5(a) and 5(b)) than untreated HD/ASCs (Figure 3S, panels A, B). By contrast, in cocultures comprising untreated and TI-treated AS/ASCs, these associations were comparable (Figures 5(e) and 5(f) versus Figure 4S, panels E, F). Thus, AS/ASCs seem to be less sensitive than HD/ASCs to TI-triggered enhancement of their functions. The priming of MSCs with proinflammatory cytokines, a procedure named "licensing," is one of several strategies to generate highly functional MSCs for therapeutic application [39].
Licensing of ASCs with TNF and/or IFN $\gamma$ was reported to enhance the immunosuppressive functions of these cells, including inhibition of T cell proliferation [60,61], which is in line with present results concerning HD/ASCs. This procedure is believed to mimic the tissue inflammatory milieu, known to promote the immunomodulatory function of MSCs [39]. Because ASCs of AS patients have been exposed in vivo to a chronic inflammatory microenvironment, and in vitro are less sensitive than ASCs of healthy donors to TI-licensing, they are presumably in vivo licensed cells of well-developed antiproliferative abilities.

Intriguingly, the correlation analysis and results of blocking experiments suggest that the contribution of kynurenines and $\mathrm{PGE}_{2}$ to the antiproliferative activity of ASCs of healthy donors and AS patients is not equal. Although both kynurenines and $\mathrm{PGE}_{2}$ were found to be essential mediators of the activity of TI-primed HD/ASCs (Figures 5(a)-5(d), 6(a)$6(\mathrm{c})$, and $7(\mathrm{a})-7(\mathrm{c}))$, they play smaller, if any, role in mediating weaker antiproliferative action of untreated HD/ASCs (Figures 6(a)-6(c), 7(a)-7(c), and 3S, panels A-D). Regarding AS/ASCs, kynurenines turned out to be the mediators of the antiproliferative activity of both TI-treated and, to a lesser extent, also untreated cells, influencing all tested parameters of proliferative response (Figures 5(e)-5(h), 6(d)-6(f), 7(d)-7(f), and 3S, panels E, F), while the contribution $\mathrm{PGE}_{2}$ to these cells function was restricted, since indomethacin counteracted the inhibitory effect of untreated and TItreated AS/ASCs on the number of proliferating T cells only (Figures 6(d)-6(f) and 7(d)-7(f)).

Because it has previously been reported that in vitro preactivated $\mathrm{T}$ cells are partly and in a time-dependent manner, resistant to antiproliferative action of ASCs [62], we finally check whether AS/ASCs can inhibit proliferation of 
autologous $\mathrm{T}$ lymphocytes-the cells chronically exposed in vivo to the inflammatory milieu. Present results show that in cocultures with allogeneic and autologous PBMCs, AS/ASCs inhibit the proliferative response of $\mathrm{CD}^{+}$and $\mathrm{CD}^{+} \mathrm{T}$ cells with similar potency (Figures $8(\mathrm{a})-8(\mathrm{f})$ ). Moreover, in both allogeneic and autologous cocultures, similar concentrations of $\mathrm{PGE}_{2}$ were found (Figure $8(\mathrm{~h})$ ), and kynurenine generation was even higher in autologous than allogeneic conditions (Figure $8(\mathrm{~g})$ ).

Our study has some limitations. Due to the gating strategy, we have used, the small contamination in the CD4+ or CD8+ subsets by other populations cannot be excluded.

\section{Conclusions}

In summary, we report, for the first time, that mesenchymal stem cells derived from adipose tissue of ankylosing spondylitis patients (AS/ASCs) are effective suppressors of both allogeneic and autologous $\mathrm{CD} 4^{+}$and $\mathrm{CD} 8^{+} \mathrm{T}$ cells, and, similarly to their counterparts from healthy donors (HD/ASCs), exert this antiproliferative effect mainly via soluble factors (kynurenines and $\mathrm{PGE}_{2}$ ). Moreover, some distinctions between the antiproliferative activity of HD/ASCs and AS/ASCs suggest in vivo licensing of the latter cells.

\section{Data Availability}

The data used to support the findings of this study are included within the article.

\section{Conflicts of Interest}

The authors declare that there is no conflict of interest regarding the publication of this paper.

\section{Acknowledgments}

We are grateful to all patients who donated their adipose tissue for our research. This study was supported financially by the National Science Centre of Poland (grant number 2016/21/B/NZ5/00500) and by core grant (grant number S/6) to the NIGRR from the Polish Ministry of Science and Higher Education.

\section{Supplementary Materials}

Figure 1S: exemplary histograms showing PHA-triggered proliferation of peripheral blood mononuclear cells (PBMCs) in various culture variants: $(\mathrm{A})$ proliferation of $\mathrm{CD} 4+$ cells; (b) the proliferation of CD8+ cells. ASCs: adipose-derived mesenchymal stem cells; TI: TNF + IFN $\gamma$ cell treatment. Figure 2S: the degree of $\mathrm{T}$ cell proliferation inhibition depends on the PBMCs donor. Two HD/ASCs lines (A, C) and two AS/ASCs lines obtained from 2 AS patients (B, D) were cocultured with PBMCs of four different donors (donors 14). Coculture condition as in Figure 1. Figure 3S: secretion of IL-10 in PHA-stimulated peripheral blood mononuclear cells cultured separately (PBMCs) or cocultured with ASCs of healthy donors (HD/ASCs) and AS patients (AS/ASCs). Cell preparation and culture conditions as described in Mate- rial and Methods. Untreated and TNF $+\mathrm{IFN} \gamma$ - (TI-) treated ASCs were used. There were no significant differences between the control of separate cultures of PBMCs and cell cocultures. $\# P=0.05-0.01$ for intergroup (HD vs. AS) comparison. Figure $4 \mathrm{~S}$ : correlation of kynurenines and $\mathrm{PGE}_{2}$ concentrations with the number of proliferating $\mathrm{T}$ cells. Cell preparation, culture conditions, evaluation of $\mathrm{CD}^{+}(\mathrm{A}, \mathrm{C}, \mathrm{E}$, $\mathrm{G})$ and $\mathrm{CD}^{+}(\mathrm{B}, \mathrm{D}, \mathrm{F}, \mathrm{H})$ cell proliferation, and the measurement of kynurenines and $\mathrm{PGE}_{2}$ concentrations as in Figure 5, except that only untreated ASCs were used. Spearman's rank (Rs) (A, B, E, F) and Pearson's $(R)(C, D, G, H)$ correlation coefficients and $P$ values are shown. Other explanations as in Figure 1. Figure 5S: lack of inverse correlation of IL-10 concentrations with the number of proliferating T cells. Cell preparation, culture conditions, and evaluation of $\mathrm{CD}^{+}(\mathrm{A}$, $\mathrm{C}, \mathrm{E}, \mathrm{G})$ and $\mathrm{CD}^{+}(\mathrm{B}, \mathrm{D}, \mathrm{F}, \mathrm{H})$ cell proliferation in the presence of untreated and TI-treated ASCs as in Figures 5 and 4S, respectively. The measurement of IL-10 concentrations in culture supernatants was performed as described in Material and Methods. Pearson's $(R)$ correlation coefficients and $P$ values are shown. Other explanations as in Figure 1. (Supplementary Materials)

\section{References}

[1] J. D. Taurog, A. Chhabra, and R. A. Colbert, "Ankylosing spondylitis and axial spondyloarthritis," New England Journal of Medicine, vol. 374, no. 26, pp. 2563-2574, 2016.

[2] D. McGonagle, S. Z. Aydin, A. Gül, A. Mahr, and H. Direskeneli, "'MHC-I-opathy'-unified concept for spondyloarthritis and Behçet disease," Nature Reviews Rheumatology, vol. 11, no. 12, pp. 731-740, 2015.

[3] A. Cortes, S. L. Pulit, P. J. Leo et al., "Major histocompatibility complex associations of ankylosing spondylitis are complex and involve further epistasis with_ERAP1_, Nature Communications, vol. 6, no. 1, p. 7146, 2015.

[4] M. Bollow and T. Fischer, "quantitative analyses of sacroiliac biopsies in spondyloarthropathies: $\mathrm{T}$ cells and macrophages predominate in early and active sacroiliitis- cellularity correlates with the degree of enhancement detected by magnetic resonance imaging," Annals of the Rheumatic Diseases, vol. 59, no. 2, pp. 135-140, 2000.

[5] J. Braun, M. Bollow, L. Neure et al., "Use of immunohistologic and in situ hybridization techniques in the examination of sacroiliac joint biopsy specimens from patients with ankylosing spondylitis," Arthritis and Rheumatism, vol. 38, no. 4, pp. 499-505, 1995.

[6] M. A. Treviño, E. Teixeiro, and R. Bragado, "CD8+ T cells oligoclonally expanded in synovial fluid at onset of spondyloarthropathy selectively proliferate in response to self-antigens: characterization of cell specificities in nonclonal populations," The Journal of Rheumatology, vol. 31, no. 10, pp. 1962-1972, 2004.

[7] P. Bowness, A. Ridley, J. Shaw et al., "Th17 cells expressing KIR3DL2+ and responsive to HLA-B27 homodimers are increased in ankylosing spondylitis," Journal of Immunology, vol. 186, no. 4, pp. 2672-2680, 2011.

[8] I. Wong-Baeza, A. Ridley, J. Shaw et al., "KIR3DL2 binds to HLA-B27 dimers and free $\mathrm{H}$ chains more strongly than other HLA class I and promotes the expansion of $\mathrm{T}$ cells in 
ankylosing spondylitis," Journal of Immunology, vol. 190, no. 7, pp. 3216-3224, 2013.

[9] A. Šućur, Z. Jajić, I. Matijašević et al., "Combined manual and automated immunophenotypisation identified disease-specific peripheral blood immune subpopulations in rheumatoid arthritis, ankylosing spondylitis and psoriatic arthritis," Clinical and Experimental Rheumatology, vol. 38, pp. 903-916, 2020.

[10] J. Cagliani, D. Grande, E. P. Molmenti, E. J. Miller, and H. L. R. Rilo, "Immunomodulation by mesenchymal stromal cells and their clinical Applications," Journal of Stem Cell and Regenerative Biology, vol. 3, no. 2, pp. 1-14, 2017.

[11] M. M. Duffy, T. Ritter, R. Ceredig, and M. D. Griffin, "Mesenchymal stem cell effects on T-cell effector pathways," Stem Cell Research \& Therapy, vol. 2, no. 4, p. 34, 2011.

[12] A. Aggarwal and M. F. Pittenger, "Human mesenchymal stem cells modulate allogeneic immune cell responses," Transplantation, vol. 105, no. 4, pp. 1815-1822, 2005.

[13] J. Su, X. Chen, Y. Huang et al., "Phylogenetic distinction of iNOS and IDO function in mesenchymal stem cell- mediated immunosuppression in mammalian species," Cell Death and Differentiation, vol. 21, no. 3, pp. 388-396, 2014.

[14] X. L. Fan, Y. Zhang, X. Li, and Q. L. Fu, "Mechanisms underlying the protective effects of mesenchymal stem cell-based therapy," Cellular and Molecular Life Sciences, vol. 77, no. 14, pp. 2771-2794, 2020.

[15] B. C. Lee and K. S. Kang, "Functional enhancement strategies for immunomodulation of mesenchymal stem cells and their therapeutic application," Stem Cell Research \& Therapy, vol. 11, no. 1, p. 397, 2020.

[16] X. Li, P. Wang, Z. Xie et al., "Whole genome expression profiling and signal pathway screening of MSCs in ankylosing spondylitis," Stem Cells International, vol. 2014, 913011 pages, 2014.

[17] Z. Xie, P. Wang, J. Li et al., "MCP1 triggers monocyte dysfunctions during abnormal osteogenic differentiation of mesenchymal stem cells in ankylosing spondylitis," Journal of Molecular Medicine, vol. 95, no. 2, pp. 143-154, 2017.

[18] Y. Wu, M. Ren, R. Yang et al., "Reduced immunomodulation potential of bone marrow-derived mesenchymal stem cells induced CCR4+CCR6+ Th/Treg cell subset imbalance in ankylosing spondylitis," Arthritis Research \& Therapy, vol. 13, no. 1, p. R29, 2011.

[19] Z. Liu, P. Wang, S. Cen et al., "Increased BMPR1A expression enhances the adipogenic differentiation of mesenchymal stem cells in patients with ankylosing spondylitis," Stem Cells International, vol. 2019, Article ID 4143167, 13 pages, 2019.

[20] G. Zheng, Z. Xie, P. Wang et al., "Enhanced osteogenic differentiation of mesenchymal stem cells in ankylosing spondylitis: a study based on a three-dimensional biomimetic environment," Cell Death \& Disease, vol. 10, no. 5, p. 350, 2019.

[21] W. Liu, P. Wang, Z. Xie et al., "Abnormal inhibition of osteoclastogenesis by mesenchymal stem cells through the miR-4284/CXCL5 axis in ankylosing spondylitis," Cell Death \& Disease, vol. 10, no. 3, p. 188, 2019.

[22] K. Abdolmohammadi, F. Pakdel, H. Aghaei et al., "Ankylosing spondylitis and mesenchymal stromal/stem cell therapy: a new therapeutic approach," Biomedicine \& Pharmacotherapy, vol. 109, pp. 1196-1205, 2019.

[23] E. Kuca-Warnawin, T. Burakowski, W. Kurowska et al., "Elevated number of recently activated $\mathrm{T}$ cells in bone marrow of patients with rheumatoid arthritis: a role for interleukin 15?," Annals of the Rheumatic Diseases, vol. 70, no. 1, pp. 227-233, 2011.

[24] B. Bright, R. Bright, P. Bright, and A. Limaye, "Ankylosing spondylitis, chronic fatigue and depression improved after stromal vascular fraction treatment for osteoarthritis: a case report," Journal of Medical Case Reports, vol. 12, no. 1, p. 238, 2018.

[25] E. Kuca-Warnawin, U. Skalska, I. Janicka et al., "The phenotype and secretory activity of adipose-derived mesenchymal stem cells (ASCs) of patients with rheumatic diseases," Cell, vol. 9, p. 1659, 2019.

[26] E. Kuca-Warnawin, I. Janicka, P. Szczęsny et al., "Modulation of T-cell activation markers expression by the adipose tissue-derived mesenchymal stem cells of patients with rheumatic diseases," Cell Transplantation, vol. 29, article 096368972094568, 2020.

[27] M. Rudwaleit, D. van der Heijde, R. Landewe et al., "The development of ASSessment of SpondyloArthritis international Society classification criteria for axial spondyloarthritis (part II): validation and final selection," Annals of the Rheumatic Diseases, vol. 68, no. 6, pp. 777-783, 2009.

[28] U. Skalska, E. Kontny, M. Prochorec-Sobieszek, and W. Maslinski, "Intra-articular adipose-derived mesenchymal stem cells from rheumatoid arthritis patients maintain the function of chondrogenic differentiation," Rheumatology (Oxford), vol. 51, no. 10, pp. 1757-1764, 2012.

[29] K. English, F. P. Barry, C. P. Field-Corbett, and B. P. Maho, "IFN- $\gamma$ and TNF- $\alpha$ differentially regulate immunomodulation by murine mesenchymal stem cells," Immunology Letters, vol. 110, no. 2, pp. 91-100, 2007.

[30] J. Cuerquis, R. Romieu-Mourez, M. François et al., "Human mesenchymal stromal cells transiently increase cytokine production by activated $\mathrm{T}$ cells before suppressing $\mathrm{T}$-cell proliferation: effect of interferon- $\gamma$ and tumor necrosis factor- $\alpha$ stimulation," Cytotherapy, vol. 16, no. 2, pp. 191202, 2014.

[31] Z. Tu, Q. Li, and H. Bu, "Mesenchymal stem cells inhibit complement activation by secreting factor H," Stem Cells and Development, vol. 19, no. 11, pp. 1803-1809, 2010.

[32] J. O. Ahn, J. S. Chae, Y. R. Coh et al., "Human adipose tissuederived mesenchymal stem cells inhibit T-cell lymphoma growth in vitro and in vivo," Anticancer Research, vol. 34, no. 9, pp. 4839-4847, 2014.

[33] G. Ren, J. Su, L. Zhang et al., "Species variation in the mechanisms of mesenchymal stem cell-mediated Immunosuppression," Stem Cells, vol. 27, no. 8, pp. 1954-1962, 2009.

[34] M. Kampera, L. Cosmi, R. Angeli et al., "Role for interferon- $\gamma$ in the immunomodulatory activity of human bone marrow mesenchymal stem cells," Stem Cells, vol. 24, no. 2, pp. 386398, 2006.

[35] I. Prigione, F. Benvenuto, P. Bocca, L. Battistini, A. Uccelli, and V. Pistoia, "Reciprocal interactions between human mesenchymal stem cells and $\gamma \delta$ T cells or invariant natural killer T cells," Stem Cells, vol. 27, no. 3, pp. 693-702, 2009.

[36] G. M. Spaggiari, A. Capobianco, H. Abdelrazik, F. Becchetti, M. C. Mingari, and L. Moretta, "Mesenchymal stem cells inhibit natural killer-cell proliferation, cytotoxicity, and cytokine production: role of indoleamine 2, 3-dioxygenase and prostaglandin E2," Blood, vol. 111, no. 3, pp. 13271333, 2008. 
[37] M. Roederer, "Interpretation of cellular proliferation data: avoid the panglossian," Cytometry. Part A, vol. 79, pp. 95$101,2011$.

[38] L. Gao, F. Liu, L. Tan, T. Liu, Z. Chen, and C. Shi, “The immunosuppressive properties of non-cultured dermal-derived mesenchymal stromal cells and the control of graft-versushost disease," Biomaterials, vol. 35, no. 11, pp. 3582-3588, 2014.

[39] Y. Seo, T. H. Shin, and H. S. Kim, "Current strategies to enhance adipose stem cell function: an update," International Journal of Molecular Sciences, vol. 20, no. 15, p. 3827, 2019.

[40] M. Najar, G. Raicevic, H. I. Boufker et al., "Mesenchymal stromal cells use PGE2 to modulate activation and proliferation of lymphocyte subsets: combined comparison of adipose tissue, Wharton's Jelly and bone marrow sources," Cellular Immunology, vol. 264, no. 2, pp. 171-179, 2010.

[41] M. Li, X. Sun, X. Kuang, Y. Liao, H. Li, and D. Luo, "Mesenchymal stem cells suppress CD8+T cell-mediated activation by suppressing natural killer group 2 , member $\mathrm{D}$ protein receptor expression and secretion of prostaglandin E2, indoleamine 2, 3-dioxygenase and transforming growth factor- $\beta$," Clinical and Experimental Immunology, vol. 178, no. 3, pp. 516-524, 2014.

[42] F. Gao, S. M. Chiu, D. A. L. Motan et al., "Mesenchymal stem cells and immunomodulation: current status and future prospects," Cell Death \& Disease, vol. 7, no. 1, article e2062, 2016.

[43] Y. Zhou, Y. Yamamoto, Z. Xiao, and T. Ochiya, "The immunomodulatory functions of mesenchymal stromal/stem cells mediated via paracrine activity," Journal of Clinical Medicine, vol. 8, no. 7, p. 1025, 2019.

[44] O. Dela Rosa, E. Lombardo, A. Beraza et al., "Requirement of IFN-gamma-mediated indoleamine 2, 3-dioxygenase expression in the modulation of lymphocyte proliferation by human adipose-derived stem cells," Tissue Engineering. Part A, vol. 15, pp. 2795-2806, 2009.

[45] R. Menta, P. Mancheño-Corvo, B. Del Rio et al., “Tryptophan concentration is the main mediator of the capacity of adipose mesenchymal stromal cells to inhibit T-lymphocyte proliferation _in vitro_," Cytotherapy, vol. 16, no. 12, pp. 1679-1691, 2014.

[46] A. L. Mellor and D. H. Munn, "Tryptophan catabolism and regulation of adaptive immunity," Journal of Immunology, vol. 170, no. 12, pp. 5809-5813, 2003.

[47] Y. Mándi and L. Vécsei, "The kynurenine system and immunoregulation," Journal of Neural Transmission, vol. 119, no. 2, pp. 197-209, 2012.

[48] E. Wirthgen, A. Hoeflich, A. Rebl, and J. Günther, "Kynurenic acid: the janus-faced role of an immunomodulatory tryptophan metabolite and its link to pathological conditions," Frontiers in Immunology, vol. 8, p. 1957, 2018.

[49] A. J. Cutler, V. Limbani, J. Girdlestone, and C. V. Navarette, "Umbilical cord-derived mesenchymal stromal cells modulate monocyte function to suppress T cell proliferation," Journal of Immunology, vol. 185, no. 11, pp. 6617-6623, 2010.

[50] D. Wang, K. Chen, W. T. Dyu et al., "CD14 ${ }^{+}$monocytes promote the immunosuppressive effect of human umbilical cord matrix stem cells," Experimental Cell Research, vol. 316, no. 15, pp. 2414-2423, 2010.

[51] R. Yañez, A. Oviedo, M. Aldea, J. A. Bueren, and M. L. Lamana, "Prostaglandin E2 plays a key role in the immunosuppressive properties of adipose and bone marrow tissue- derived mesenchymal stromal cells," Experimental Cell Research, vol. 316, no. 19, pp. 3109-3123, 2010.

[52] V. Sreeramkumar, M. Fresno, and N. Cuesta, "Prostaglandin E2 and T cells: friends or foes?," Immunology and Cell Biology, vol. 90, no. 6, pp. 579-586, 2012.

[53] W. J. Sander, H. G. O’Neill, and C. H. Pohl, "Prostaglandin E2 as a modulator of viral infections," Frontiers in Physiology, vol. 8, p. 89, 2017.

[54] M. S. von Berfgwelt-Baildon, A. Popov, T. Saric et al., "CD25 and indoleamine 2, 3-dioxygenase are up-regulated by prostaglandin E2 and expressed by tumor-associated dendritic cells in vivo: additional mechanisms of T-cell inhibition," Blood, vol. 108, no. 1, pp. 228-237, 2006.

[55] M. E. Quaedackers, C. C. Baan, W. Weimar, and M. J. Hoogduijn, "Cell contact interaction between adiposederived stromal cells and allo-activated T lymphocytes," European Journal of Immunology, vol. 39, no. 12, pp. 3436-3446, 2009.

[56] M. E. Healy, R. Bergin, B. P. Mahon, and K. English, "Mesenchymal stromal cells protect against caspase 3mediated apoptosis of CD19+peripheral B cells through contact-dependent upregulation of VEGF," Stem Cells and Development, vol. 24, no. 20, pp. 2391-2402, 2015.

[57] G. Li Pira, F. Ivaldi, L. Bottone, R. Quarto, and F. Manca, "Human Bone Marrow Stromal Cells Hamper Specific Interactions of CD4 and CD8 T Lymphocytes with AntigenPresenting Cells," Human Immunology, vol. 67, no. 12, pp. 976-985, 2006.

[58] S. Liu, F. Liu, Y. Zhou, B. Jin, Q. Sun, and S. Guo, "Immunosuppressive Property of MSCs Mediated by Cell Surface Receptors," Frontiers in Immunology, vol. 11, p. 1076, 2020.

[59] D. Campioni, R. Rizzo, M. Stignani et al., "A decreased positivity for CD90 on human mesenchymal stromal cells (MSCs) is associated with a loss of immunosuppressive activity by MSCs," Cytometry, vol. 76B, no. 3, pp. 225-230, 2009.

[60] R. Domenis, A. Cifu, S. Quaglia et al., "Pro-inflammatory stimuli enhance the immunosuppressive functions of adipose mesenchymal stem cells-derived exosomes," Scientific Reports, vol. 8, article 13325, 2018.

[61] T. R. T. Serejo, A. E. Silva-Carvalho, L. D. C. F. Braga et al., "Assessment of the immunosuppressive potential of INF- $\gamma$ licensed adipose mesenchymal stem cells, their secretome and extracellular vesicles," Cell, vol. 8, p. 22, 2019.

[62] P. Mancheño-Corvo, R. Menta, B. del Rio et al., "T lymphocyte prestimulation impairs in a time-dependent manner the capacity of adipose mesenchymal stem cells to inhibit proliferation: role of interferon $\gamma$, poly I:C, and tryptophan metabolism in restoring adipose mesenchymal stem cell inhibitory effect," Stem Cells and Development, vol. 24, no. 18, pp. 2158-2170, 2015. 